\title{
Prediction and Diagnosis of Typhoon Morakot (2009) Using the Naval Research Laboratory's Mesoscale Tropical Cyclone Model
}

\author{
Eric A. Hendricks ${ }^{1, *}$, Jonathan R. Moskaitis ${ }^{1}$, Yi Jin ${ }^{1}$, Richard M. Hodur ${ }^{2}$, James D. Doyle ${ }^{1}$, \\ and Melinda S. Peng ${ }^{1}$ \\ ${ }^{1}$ Marine Meteorology Division, Naval Research Laboratory, Monterey, CA, USA \\ ${ }^{2}$ Science Applications International Corporation, Monterey, CA, USA
}

Received 17 February 2011, accepted 30 May 2011

\begin{abstract}
Numerical simulations of Typhoon Morakot (2009) were performed using the Naval Research Laboratory's Coupled Ocean/Atmosphere Mesoscale Prediction System for Tropical Cyclones (COAMPS-TC). COAMPS-TC was run in real-time in 2009 in the western North Pacific Ocean basin, and simulations of Morakot were executed during its life cycle, from formation through landfall in Taiwan. In this work, an evaluation of the model's performance is presented. The COAMPS-TC average track errors were small and very close to those of the consensus. Further, the intensity errors were small; the mean absolute intensity error at the $48 \mathrm{~h}$ lead time was $9 \mathrm{kt}$. Particular focus was placed on the 72-h simulation beginning on 1200 UTC 6 August, encompassing the time frame before, during and after landfall. COAMPS-TC was able to predict the structure of Morakot reasonably well before and after landfall, capturing a large asymmetric tropical cyclone with the precipitation shield shifted to the south of its center. Qualitatively, the precipitation forecast was consistent with observations from the Taiwan rain gauge network, as the model was able to predict two maxima, in both the northern and southern portions of the central mountain range. However, the accumulated precipitation maximum in the southern portion of the central mountain range was underpredicted by approximately $50 \%$. The underprediction in precipitation by COAMPS-TC in southern Taiwan was due to four factors: (i) the premature dissipation of tropical storm Goni causing errors in the large-scale flow and moisture pattern after landfall, (ii) inaccuracies in the spatial location and timing of convective and stratiform precipitation as Morakot interacted with land and the southwest monsoon flow, (iii) a simulated track that moved slightly too slow prior to landfall and slightly too fast after landfall, and (iv) a horizontal resolution $(5-\mathrm{km})$ that may be too coarse to resolve the interaction of convection with the complex topography.
\end{abstract}

Key words: Typhoon, Precipitation, Numerical prediction

Citation: Hendricks, E. A., J. R. Moskaitis, Y. Jin, R. M. Hodur, J. D. Doyle, and M. S. Peng, 2011: Prediction and diagnosis of Typhoon Morakot (2009) using the Naval Research Laboratory's mesoscale tropical cyclone model. Terr. Atmos. Ocean. Sci., 22, 579-594, doi: 10.3319/TAO.2011.05.30.01(TM)

\section{INTRODUCTION}

Typhoon Morakot (2009) was the deadliest typhoon to impact Taiwan in recorded history. Although it made landfall as a weak typhoon, the interaction of the horizontally large typhoon with Taiwan's orography and the southwest monsoon flow caused extreme precipitation of approximately $2855 \mathrm{~mm}$ in the southwest portion of Taiwan, exceeding the previous record of Typhoon Herb (1996) by approximately $1000 \mathrm{~mm}$. The extreme precipitation caused

\footnotetext{
* Corresponding author

E-mail:eric.hendricks@nrlmry.navy.mil
}

mudslides that killed approximately 650 people, primarily from the catastrophic burying of the city of Xiaolin. Damages directly attributed to Morakot exceeded 110 billion NTD (source: www.hurricanescience.org). The aftermath of Morakot heightened the importance of accurately predicting typhoon-induced precipitation in addition to the more conventional parameters of wind speed, structure, and storm surge. It also re-emphasized the importance of more accurately predicting precipitation and other impacts from typhoons interacting with complex topography (Wu and Kuo 1999; Peng and Chang 2002). 
Precipitation in Taiwan in the warm season is caused mainly by monsoon- and typhoon-induced rainfall. Even though typhoons are relatively infrequent, typhoon-induced rainfall contributes to nearly half of all precipitation in Taiwan (Kubota and Wang 2009; Chen et al. 2010). Thus, the prediction of typhoon-induced rainfall is of utmost importance to Taiwan's Central Weather Bureau. However, the numerical prediction of typhoon-induced rainfall is a daunting task (Elsberry 2002). In order to obtain an accurate numerical quantitative precipitation forecast for a landfalling typhoon, there first needs to be an accurate track (including the proper timing of landfall), intensity, and structure (including convective precipitation from the eyewall and rainbands, as well as the larger regions of stratiform precipitation) prediction by the numerical model. The structure prediction is dependent both on internally generated storm asymmetries (e.g., convectively coupled vortex Rossby waves) as well as storm asymmetries caused by the environment (e.g., vertical wind shear; Rogers et al. 2003; Chen et al. 2006). In addition, the numerical model needs to be run at high enough resolution to resolve the transient deep convective features that produce heavy precipitation. Prediction is further complicated by the interaction of a typhoon with orography (Chang 1982; Bender et al. 1987; Yeh and Elsberry 1993a, b; Wu and Kuo 1999; Peng and Chang 2002; Kimball 2008; Dong et al. 2010), or interaction with synoptic-scale features, such as a typhoon undergoing extratropical transition or interaction with a monsoon. Finally, the limits of predictability for mesoscale initial value problems further limit the ability of a single state-of-the-art deterministic simulation to accurately predict the precipitation for any given typhoon. Zhang et al. (2010) has recently found that a mesoscale ensemble system can be used to give forecasters more confidence for predicting extreme rain events such as Morakot. Taking into account the inherent lack of predictability of precipitation, simpler parametric models (Lonfat et al. 2007) or analog techniques (Liu et al. 2010) may be used by warning centers to obtain estimates of expected precipitation.

Typhoon Morakot formed in the monsoon gyre of the western north Pacific ocean basin on 1800 UTC 3 August 2009. It intensified into a tropical storm, then was declared a severe tropical storm before reaching its peak intensity as a category 2 typhoon on 1200 UTC 6 August, with maximum sustained surface winds of $80 \mathrm{kt}\left(1 \mathrm{kt}=0.5144 \mathrm{~m} \mathrm{~s}^{-1}\right)$ and a minimum central pressure of $963 \mathrm{hPa}$ (Joint Typhoon Warning Center). Subsequently, Morakot moved slowly westward making landfall around 1800 UTC 7 August, and then weakened to an intensity of $55 \mathrm{kt}$. Morakot then moved northwest across Taiwan and the Taiwan Strait and then made a second landall in southeastern China on 1200 UTC 9 August as a weak tropical storm. An outstanding question with regard to Morakot is what factors caused the extreme precipitation amounts, considering it was only a weak typhoon at landfall? Another outstanding question is how well can high impact precipitation events such as Morakot be predicted with numerical models? Morakot was a complex synoptic event with many different factors combining together to produce inordinately large precipitation amounts (Nguyen and Chen 2011). Two important factors were its slow movement over Taiwan and its very large size. Another important factor was the interaction of Morakot's circulation with the southwest East Asian monsoon flow and tropical cyclones Goni and Etau (also in the monsoon gyre circulation), creating a surge of strong low-level moist flow impinging on Taiwan's western slopes. The strong moisture convergence there and interaction with the steep and complex topography caused massive amounts of rainfall. The interaction with topography cannot be overstated for the Morakot case; in a sensitivity test with reduced topography using a cloud resolving mesoscale numerical model, Ge et al. (2010) found the precipitation amounts were drastically reduced (by over 50\%) in the southern portion of the central mountain range due to the reduction in upslope forcing. Additionally, the simulated track was found to be mostly controlled by the large-scale monsoon gyre circulation, and relatively insensitive to the topography.

The Coupled Ocean/Atmosphere Mesoscale Prediction System for Tropical Cyclones (hereafter COAMPS-TC) is a mesoscale tropical cyclone (hereafter TC) prediction capability developed by the Naval Research Laboratory. COAMPS-TC was run in real time in the western north Pacific basin during 2009. Here, we present the results of the real-time COAMPS-TC run of Typhoon Morakot, and examine the mesoscale model's ability to predict the observed structure, intensity, track, and precipitation associated with Morakot. This work lends insight into how well a mesoscale model run at near cloud resolving resolutions can predict the precipitation from rare high impact events such as Morakot. In section 2, the COAMPS-TC model is described and the setup for the Morakot simulation is discussed. The observational data sources are also described. In section 3, comparisons are made between the model-predicted and observed track, intensity, structure, and precipitation. Diagnostics of the large scale evolution are also presented. A summary of the findings is provided in section 4 .

\section{DATA AND METHODS}

\subsection{Mesoscale TC Prediction Model}

The mesoscale model used here is the Coupled Ocean/ Atmosphere Mesoscale Prediction System. A description of the original COAMPS $®$ model is provided by Hodur (1997) and more details can also be found in Chen et al. (2003). The model uses a terrain following sigma-height coordinate and the non-hydrostatic compressible equations of motion (Klemp and Wilhelmson 1978). The microphysics scheme is based on Rutledge and Hobbs (1983), with prognostic 
equations for mixing ratios of cloud droplets, ice particles, rain, snow, graupel, and drizzle. The model also includes a shortwave and longwave radiation scheme (Harshvardhan et al. 1987), and a planetary boundary layer scheme with a 1.5-order turbulence closure (Mellor and Yamada 1982).

The tropical cyclone version COAMPS-TC includes the following enhancements: (i) synthetic wind and mass observations of the TC based on the operational warning message (Liou and Sashegyi 2011), (ii) relocation of the firstguess field to the observed TC position, (iii) TC-following nested inner grids using an automatic TC tracker, (iv) dissipative heating (Jin et al. 2007), and (v) a surface drag coefficient that approaches $2.5 \times 10^{-3}$ for wind speeds exceeding $35 \mathrm{~m} \mathrm{~s}^{-1}$ (Donelan et al. 2004). The forecast system also has a capability for ocean coupling; however, for this study the model was run in a standalone atmosphere mode. For the initial first-guess, the Navy Operational Global Atmospheric Prediction System (NOGAPS; Hogan and Rosmond 1991) analysis was used, and for all subsequent TC forecasts, the previous COAMPS-TC forecast was used as the first guess. As stated above, the tropical cyclone structure and intensity are included in the analysis using synthetic observations. Wind, geopotential height, and temperature data are assimilated at eight azimuthal segments and at radii of $0.5,1,2,4$, and 6 degrees from the TC center with a prescribed vertical decay to $400 \mathrm{hPa}$ (Liou and Sashegyi 2011). Above the boundary layer, the geopotential and temperature synthetic observations are determined by enforcing gradient and hydrostatic balance contraints on the winds. Note that while these synthetic observations are added for all TCs that exist at the initialization time, the high resolution moving nests (discussed in the next paragraph) are designed to follow one TC at at time. A three-dimensional variational data assimilation system (Daley and Barker 2001) was used to optimally blend the TC synthetic observations and all the conventional observations with the first-guess to obtain the analysis.

For the experiments conducted here, three nested grids were used, with horizontal resolutions of 45,15 , and $5 \mathrm{~km}$, respectively. The 15 and $5 \mathrm{~km}$ grids automatically moved to follow the TC circulation, while the $45 \mathrm{~km}$ grid was held fixed. Two-way interactive nesting was used. The setup of all three domains for COAMPS-TC in the western north Pacific basin is shown in Fig. 1. The model was run with 40 sigma levels in the vertical with a top at $31 \mathrm{~km}$, and an update cycle of $12 \mathrm{~h}$ was used. While the microphysics scheme was used for all three nests, the Kain-Fritsch cumulus scheme was activated in the 45 and $15 \mathrm{~km}$ domains to help resolve sub-grid scale convection.

In the real time setup of 2009 , the first 72 hour COAMPS-TC forecast of Morakot was run on 0000 UTC 4 August, which is referred to as the cold start because the first guess was provided by the global model NOGAPS. Subsequently, forecasts were run every 12 hours afterwards that used the previous COAMPS-TC forecast as the first guess (warm starts), until the final forecast on 1200 UTC 9 August. In this work, we primarily focus on the 72 hour forecast beginning on 1200 UTC 6 August. This specific date-time-group was chosen because it was initialized approximately 30 hours before landfall, and thus captures the time period prior, during and after landfall.

\subsection{Observational Data}

The observed estimates of the track and intensity in this study were provided by the Joint Typhoon Warning Center (JTWC). For intensity, the JTWC best track estimated maximum sustained 1-minute wind at $10 \mathrm{~m}$ above the surface is compared to the same quantity calculated from the numerical model. The observed precipitation estimate was provided by the rain gauge network of Taiwan, and interpolated to an equally spaced grid using a Barnes analysis. The observed structure of Morakot was assessed using the $85 \mathrm{GHz}$ channel from the Special Sensor Microwave Imager (SSMI), courtesy of the Naval Research Laboratory in Monterey, CA USA. The $85 \mathrm{GHz}$ channel is sensitive to ice particles in clouds, and is compared to the simulated radar reflectivity from COAMPS-TC as a proxy for areas of large precipitation rates. In order to validate the COAMPS-TC total precipitable water forecast, the satellite derived total precipitable water blended product of the Advanced Microwave Scanning Radiometer for EOS (AMSR-E) and SSMI is used, courtesy of the Cooperative Institute for Meteorological Satellite Studies (CIMSS). More details on this Morphed Integrated Microwave Imagery at CIMSS (MIMIC) product can be found in Wimmers and Velden (2007). The NOGAPS global analysis at $1^{\circ} \times 1^{\circ}$ resolution was treated as a proxy for the real atmosphere for validating the largescale forecast.

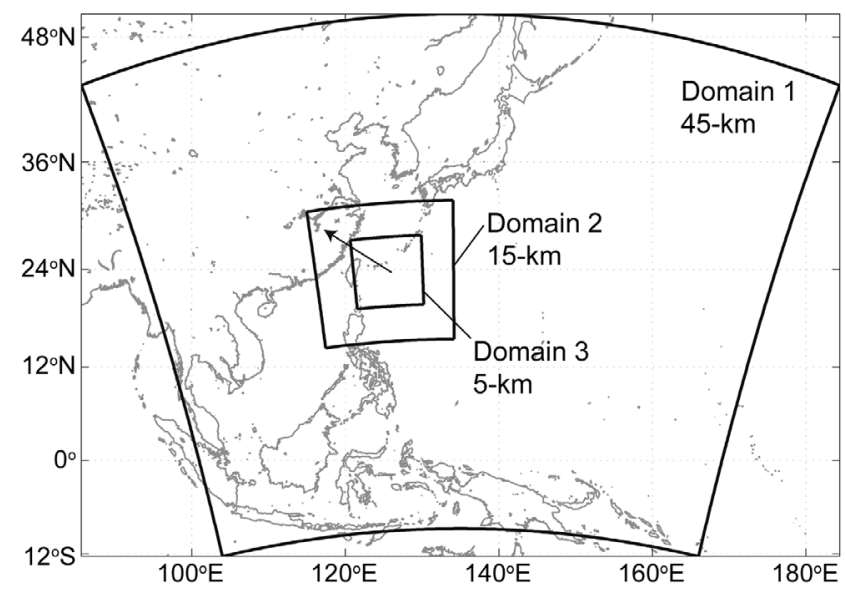

Fig. 1. Setup of the 3 domains in COAMPS-TC. The outermost domain has a horizontal resolution of $45-\mathrm{km}$ and is held fixed. The two inner domains have horizontal resolutions of $15-$ and $5-\mathrm{km}$, respectively, and move with the TC. 


\section{RESULTS}

\subsection{Track, Intensity, Structure, and Precipitation}

A comparison of the observed and predicted track for the 1200 UTC 6 August warm start is given in Fig. 2. The COAMPS-TC forecast is in gray shading, and the JTWC best track estimates are in black. With regard to the track, COAMPS-TC performed reasonably well. Initially the speed was close to the best track estimate, but just prior to landfall the simulated movement was too slow in comparison to observations. Subsequently the simulated landfall happened at 0600 UTC 8 August, approximately 12 hours later than the observed landfall at 1800 UTC 7 August. After landfall, the COAMPS-TC forecast performed well, taking the TC to the northwest consistent with the best track estimate. However, the simulated TC moved faster after landfall than the observed TC (Fig. 2), which is one factor that may have contributed to the underprediction of precipitation. The intensity comparison is made using the metric of the maximum 1-minute sustained wind at $10 \mathrm{~m}$ above the surface and is shown in the right panel of Fig. 2. As shown, COAMPS-TC predicted the gradual weakening of Morakot well.
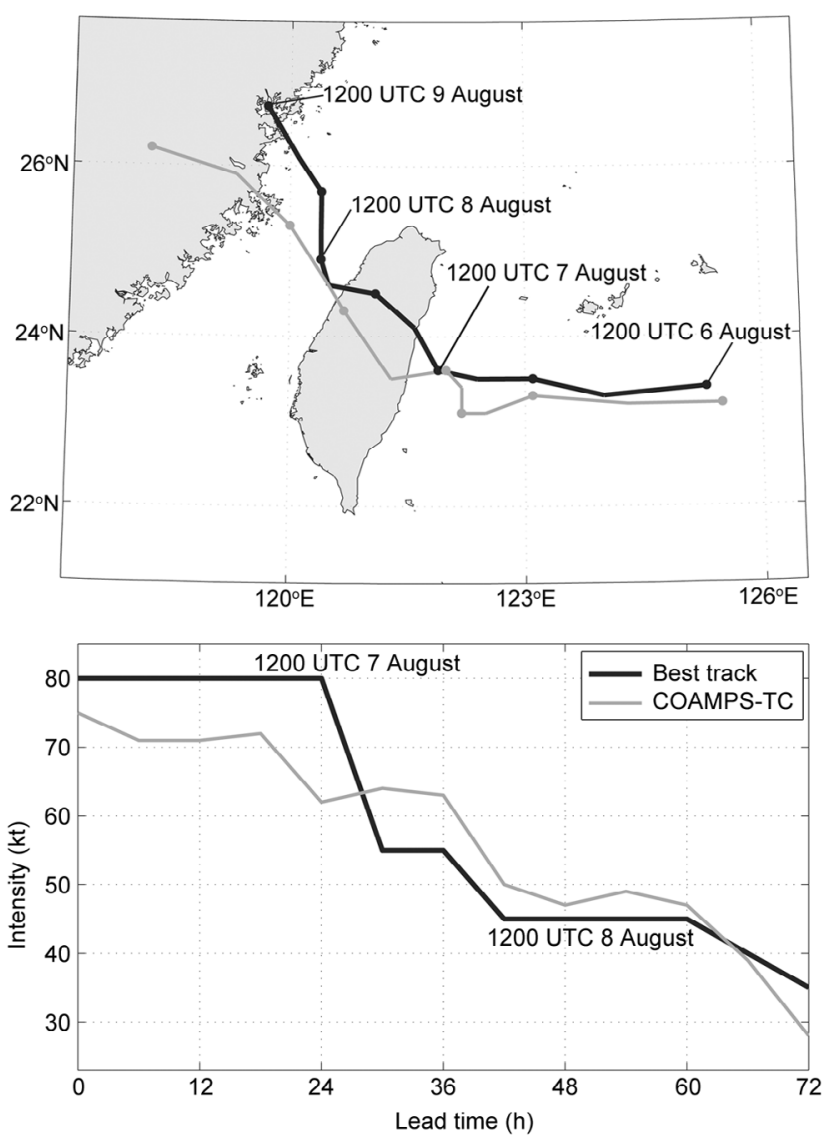

Fig. 2. Comparison of the COAMPS-TC track and intensity of the warm start forecast initialized on 1200 UTC 6 August to the JTWC best track. In the upper panel, each dot is 12-h apart. Time labels are added on both panels for the best track data.
A comparison between the simulated and observed structure is shown in Fig. 3. Here, the SSMI $85 \mathrm{GHz}$ channel is compared in a qualitative sense to the COAMPS-TC forecasted radar reflectivity at $t=18$ and $t=42 \mathrm{~h}$. At the valid time of 0600 UTC 7 August, COAMPS-TC predicts the higher reflectivities south of the TC center, in southern Taiwan, and to the east of the TC center (consistent with observations). In addition, COAMPS-TC predicts a sharp spiral feature to the north of the TC center which was also observed. However, COAMPS-TC overpredicts the precipitation to the far northwest of the TC at this time in comparison to the observations. At the valid time of 0600 UTC 8 August (after Morakot made landfall), both the observed and predicted convective patterns are less organized and the TC center is more ill-defined. However, COAMPS-TC has high reflectivity in southern Taiwan consistent with the observations, and convection occurring to the east and north of the TC, also consistent with the observations. It is possible that the disorganized structure of Morakot after landfall is a result of a discontinuous track over Taiwan (cf. Yeh and Elsberry 1993b), more common for TCs making landfall in the central and southern part of the island. At this time, however, COAMPS-TC is not able to capture the region of large precipitation in southern Taiwan. This region persisted for approximately another $18 \mathrm{~h}$ as the Morakot circulation interacted with the southwest monsoon and Taiwan's terrain, causing tremendous amounts of precipitation. The spatial location error of this feature in the numerical model forecast was a contributing factor to the underprediction in precipitation between $\mathrm{t}=48-72 \mathrm{~h}$.

In Fig. 4, the evolution of the sea level pressure and $850-\mathrm{hPa}$ relative vorticity and winds are shown at $\mathrm{t}=12,36$, and $60 \mathrm{~h}$. During the forecast, the pressure fills and the vorticity core first becomes elongated with southwest to northeast orientation prior to landfall, and then becomes more fragmented and weaker as the TC interacts with Taiwan's topography. The large cyclonic circulation associated with Morakot caused first northwesterly, then westerly flow of approximately $10-20 \mathrm{~m} \mathrm{~s}^{-1}$ to impinge on the southern part of the central mountain range, causing persistent upslope flow and enhanced precipitation.

Contour plots of the simulated and observed precipitation for 24-, 48-, and 72-h accumulation windows beginning on 1200 UTC 6 August are given in Fig. 5, and peak values for various accumulation windows are given in Table 1. As shown in Fig. 5a, the 24-h model prediction compares favorably with the observations from Taiwan's rain gauge network. The model is able to capture both maxima in the northern and southern central mountain range. However, the northern precipitation maximum is displaced slightly too far east. By 1200 UTC 8 August (48-h), the actual Morakot had made landfall and was in the Taiwan Strait (Fig. 2) while the simulated storm was still over Taiwan (Fig. 2). This track error (movement too slow prior to landfall) is one factor 
that caused an underprediction in precipitation, reflected in the 48 -h precipitation plots (Fig. 5 b). While qualitatively the simulation is able to capture the northern and southern maxima, the peak value of precipitation is underpredicted by $60 \%$ (Table 1). Moving to Fig. 5c, again the model was able to capture both the northern and southern areas of enhanced precipitation. However the magnitude of the extreme precipitation predicted by COAMPS-TC (peak value of $1318.7 \mathrm{~mm}$, Table 1) in the southern mountains was approximately half as much as was observed (peak value of $2644.5 \mathrm{~mm}$, Table 1), and COAMPS-TC was not able to simulate the large precipitation amounts near the southwest coast of Taiwan. In order to examine the precipitation comparison more closely, in Fig. 6 contour plots of the dif- ferences between the simulated and observed accumulated precipitation for different accumulation windows are given: before landfall (1200 UTC 6 August - 1200 UTC 7 August; Fig. 6a), during landfall (1200 UTC 7 August - 1200 UTC 8 August; Fig. 6b), after Morakot had exited Taiwan (1200 UTC 8 August - 1200 UTC 9 August; Fig. 6c), and the total difference between 1200 UTC 6 August and 1200 UTC 9 August (Fig. 6d). Prior to landfall, the difference between the modeled and observed precipitation is rather small, except for some localized regions. As shown in Fig. 6a, there was a slight overprediction in the southern central mountain range and eastern side of the northern central mountain range, and an underprediction on the western side of the northern central mountain range. As Morakot made landfall

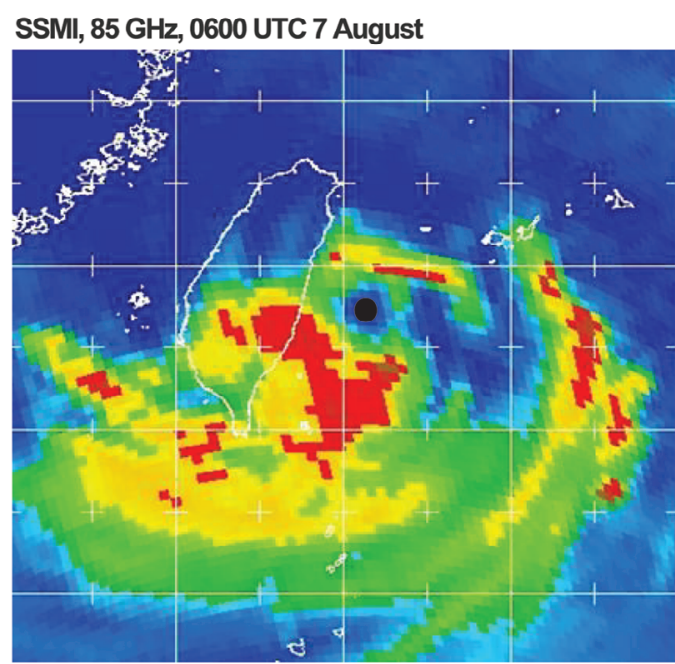

SSMI, 85 GHz, 0600 UTC 8 August

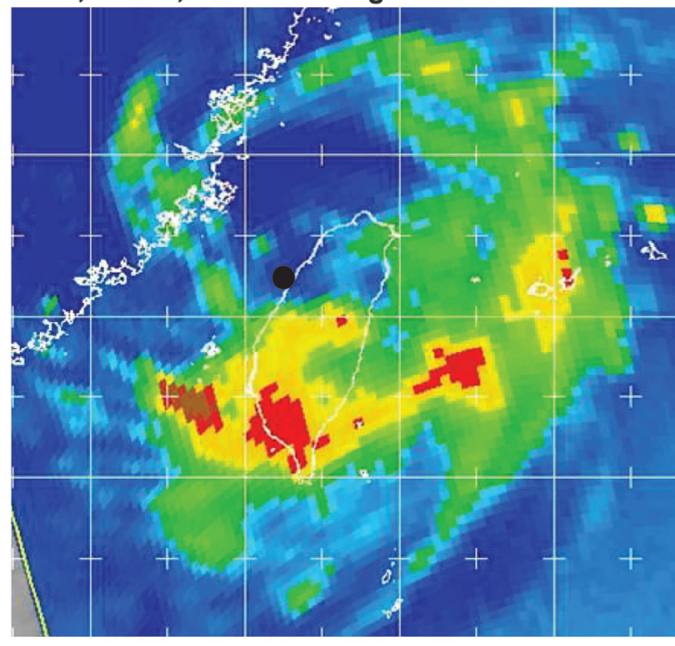

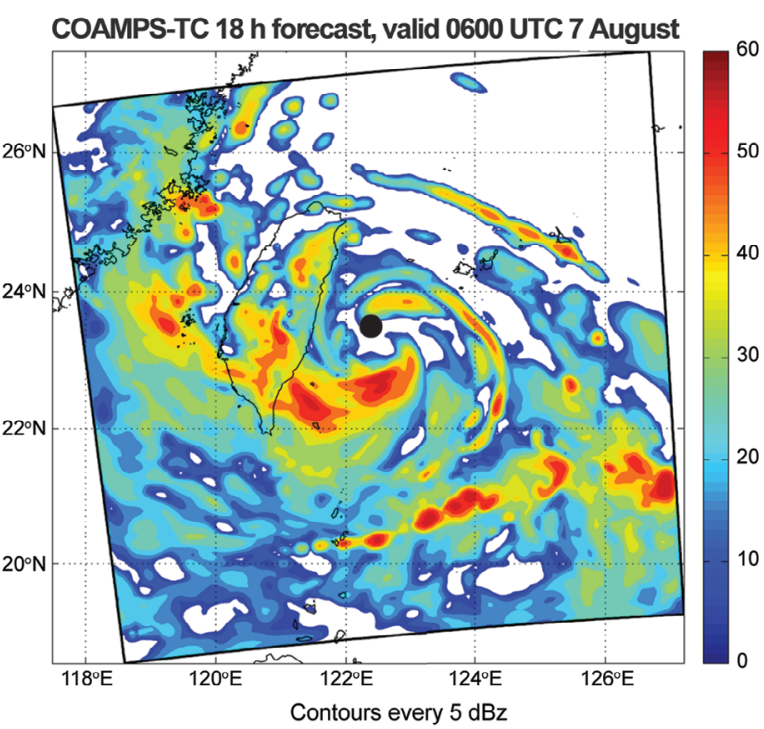

COAMPS-TC 42 h forecast, valid 0600 UTC 8 August

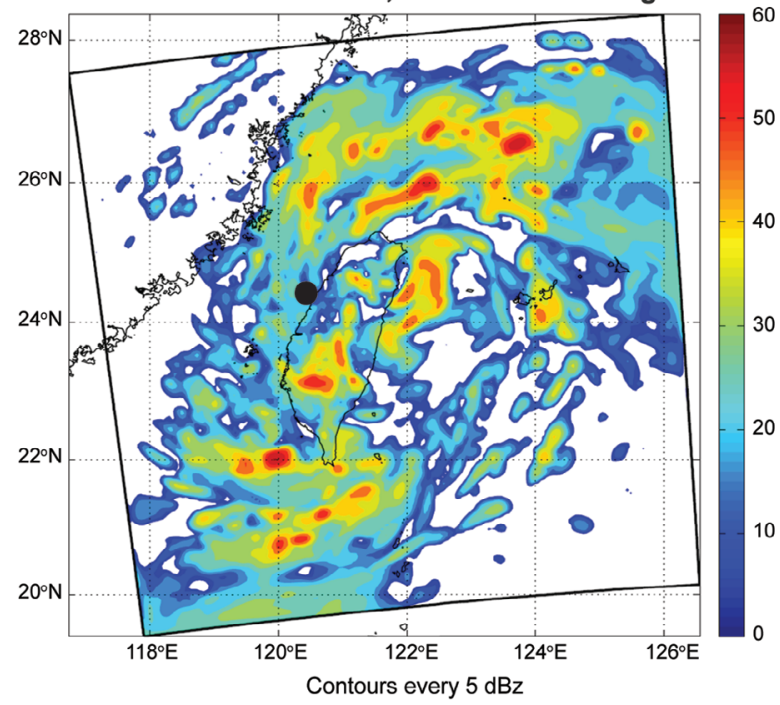

Fig. 3. Comparison of the COAMPS-TC structure forecast with microwave observations. In the left panels, the SSMI 85 GHz plots are shown, with brighter colors denoting more scattering by ice hydrometeors. In the right panels, the COAMPS-TC forecasted radar reflectivity is shown at the valid times. The observational data is courtesy of the Naval Research Laboratory in Monterey, CA USA. In each panel, the black dot denotes the position of Morakot from JTWC at the valid time. 
(a) Sea level pressure $(\mathrm{hPa}), \mathrm{t}=12 \mathrm{~h}$, valid 0000 UTC 7 August

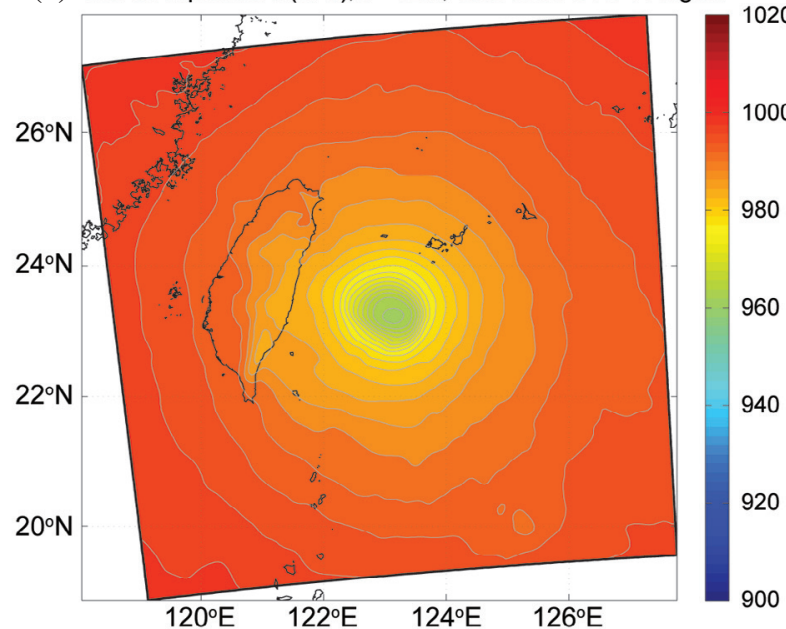

Contours every $2 \mathrm{mb}$, Minimum slp $=961 \mathrm{mb}$

(c) Sea level pressure (hPa), t $=36 \mathrm{~h}$, valid 0000 UTC 8 August

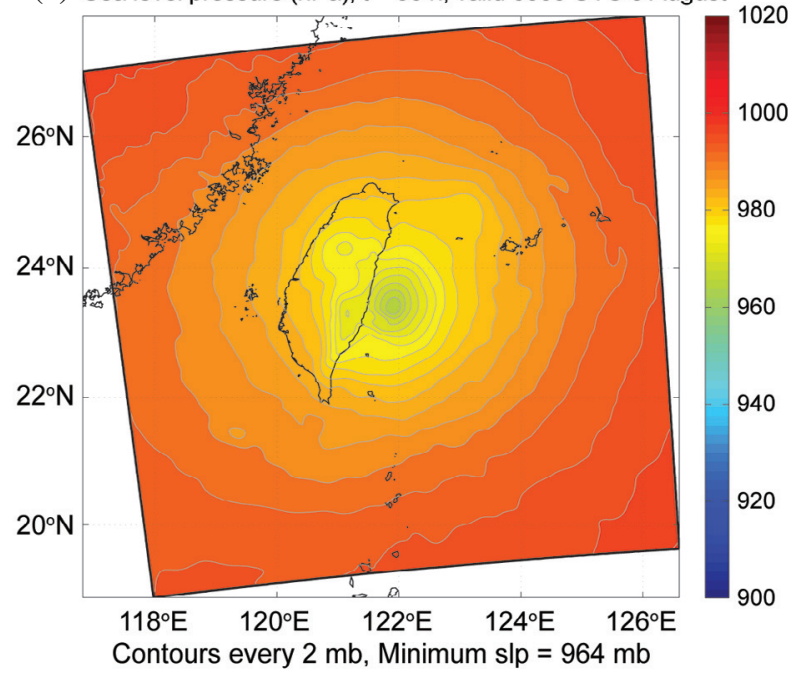

(e) Sea level pressure (hPa), t $=60 \mathrm{~h}$, valid 0000 UTC 9 August

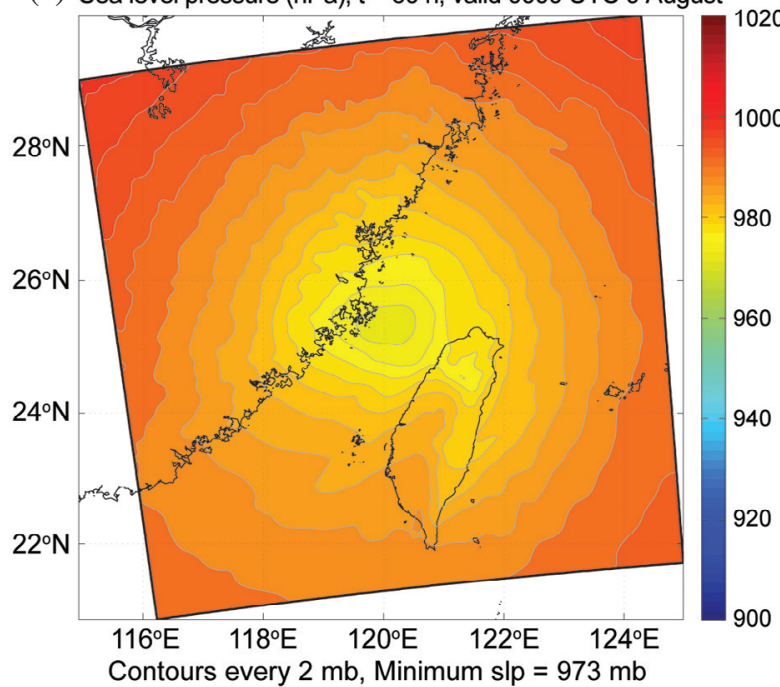

(b) $850 \mathrm{hPa}$ vorticity (1/s) and winds, $\mathrm{t}=12 \mathrm{~h}$, valid 0000 UTC 7 August

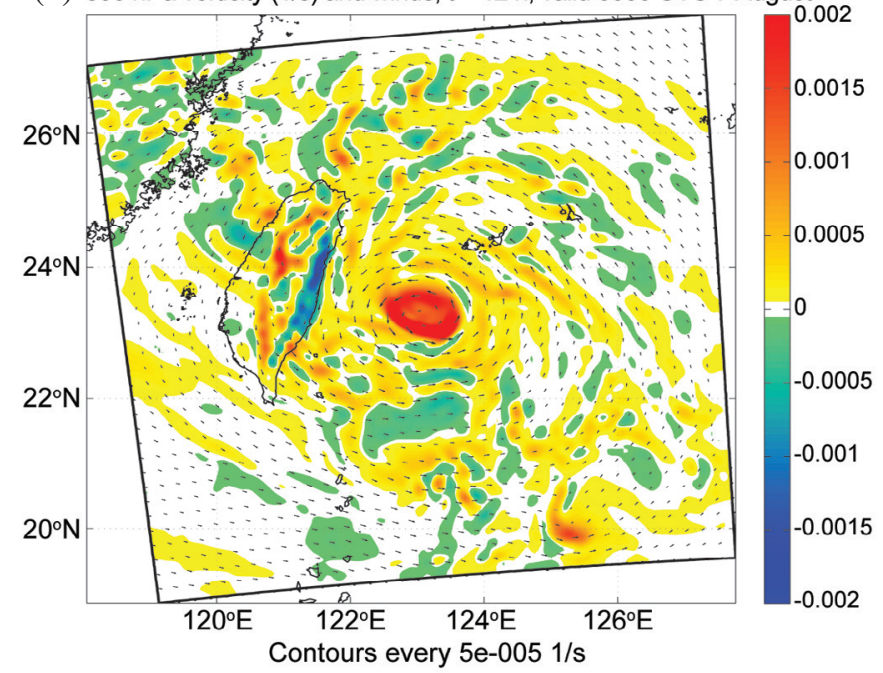

(d) $850 \mathrm{hPa}$ vorticity (1/s) and winds, t $=36 \mathrm{~h}$, valid 0000 UTC 8 August

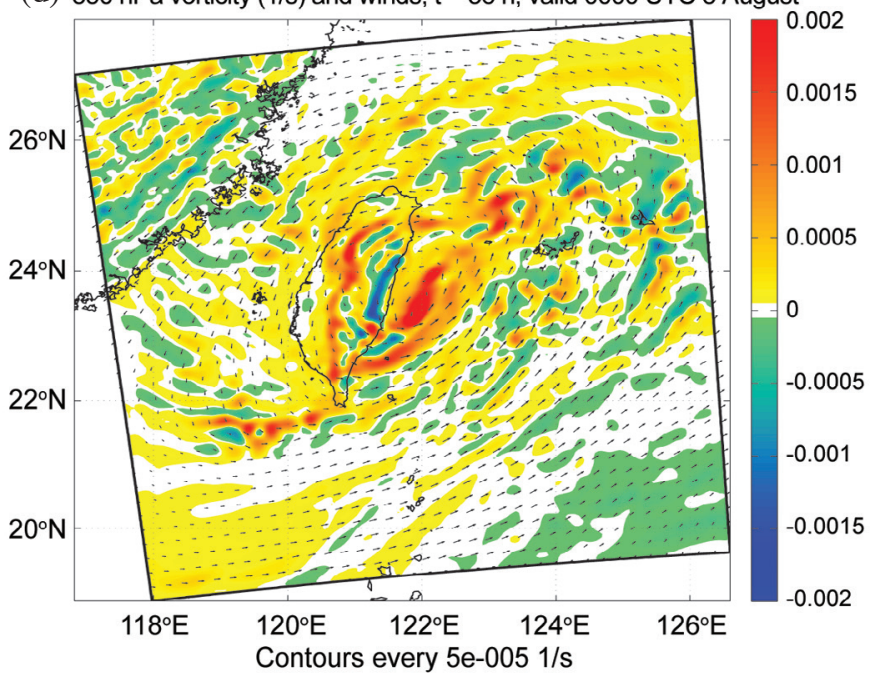

(f) $850 \mathrm{hPa}$ vorticity (1/s) and winds, t $=60 \mathrm{~h}$, valid 0000 UTC 9 August

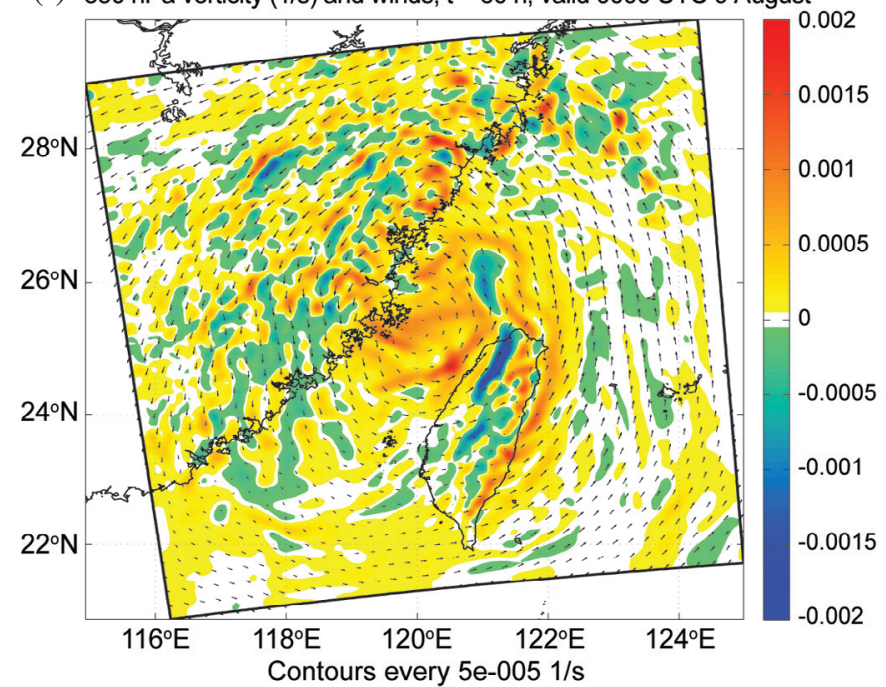

Fig. 4. Evolution of the sea level pressure and $850 \mathrm{hPa}$ relative vorticity (with $850 \mathrm{hPa}$ wind vectors overlayed) on Domain 3 (5-km horizontal resolution). 
(a) 24-h Observations (mm) .

(b) 48-h Observations (mm).

(c) 72-h Observations (mm!)
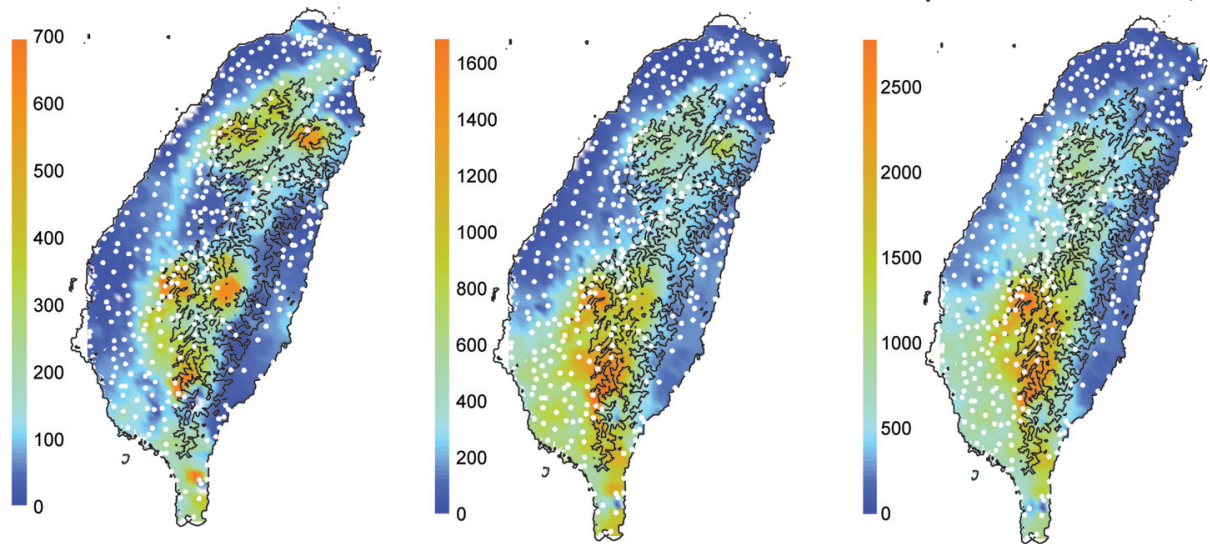

24-h Model Prediction (mm)

48-h Model Prediction ( $\mathrm{mm}$ )

72-h Model Prediction ( $\mathrm{mm}$ )
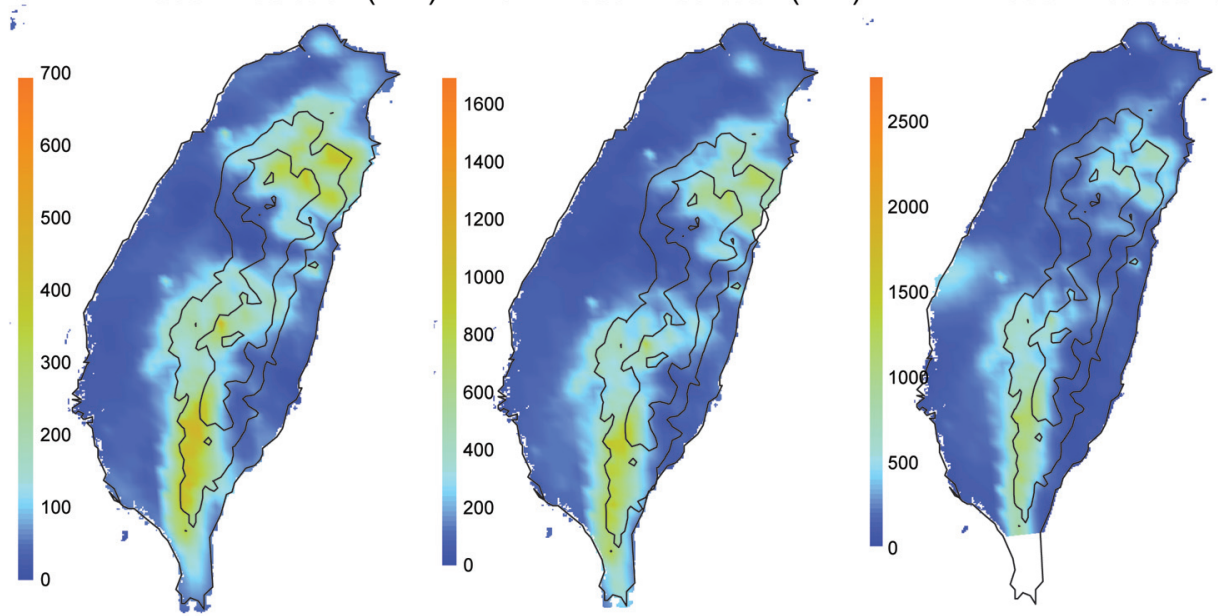

(d) Topography (m)

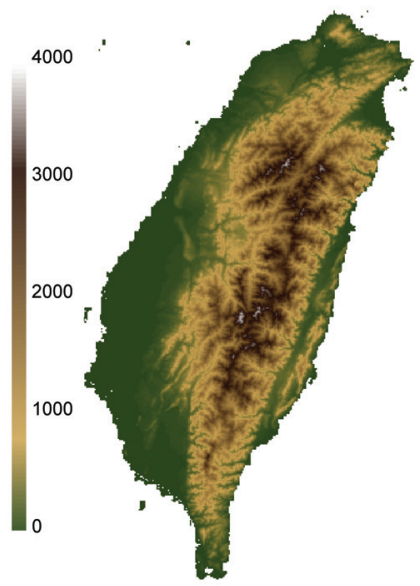

Fig. 5. Panels: (a) Comparison of the $24 \mathrm{~h}$ accumulated precipitation from 1200 UTC 6 August - 1200 UTC 7 August from the observations (top) and the COAMPS-TC prediction (bottom). (b) Same as panel (a), except for 48-h accumulated precipitation from 1200 UTC 6 August - 1200 UTC 8 August, (c) Same as panel (a), except for 72-h accumulated precipitation from 1200 UTC 6 August - 1200 UTC 9 August, and (d) Taiwan topography. Note that the contour levels are different for each precipitation panel.

Table 1. Peak accumulated precipitation amounts from observations and the numerical simulation of Morakot in COAMPS-TC.

\begin{tabular}{cccc}
\hline Accumulation Window & Duration (h) & Observed (mm) & Simulated (mm) \\
\hline 1200 UTC 6 August - 1200 UTC 7 August & 24 & 829.5 & 453.2 \\
1200 UTC 7 August - 1200 UTC 8 August & 24 & 1396.5 & 556.4 \\
1200 UTC 8 August - 1200 UTC 9 August & 24 & 1243.5 & 359.1 \\
1200 UTC 6 August - 1200 UTC 8 August & 48 & 2003.0 & 959.6 \\
1200 UTC 6 August - 1200 UTC 9 August & 72 & & \\
\hline
\end{tabular}


(a)

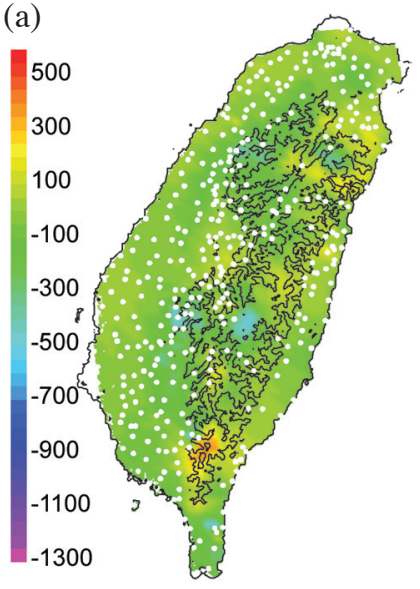

(b)

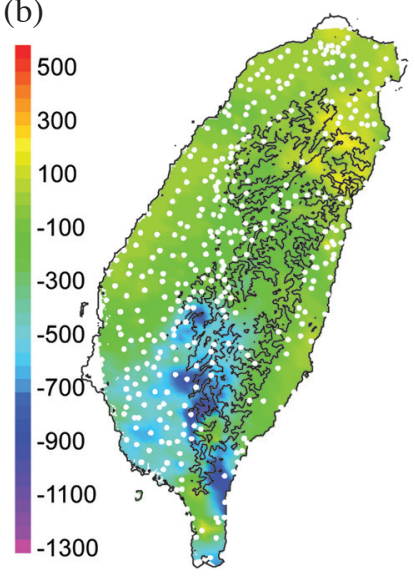

(c)

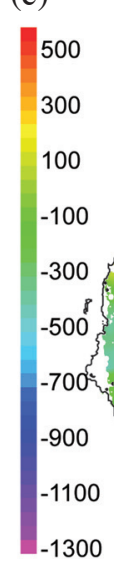

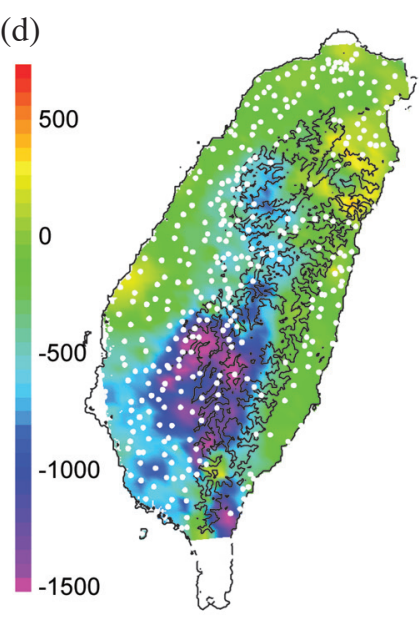

Fig. 6. Panels: (a) Difference between the predicted and observed 24-h accumulated precipitation from 1200 UTC 6 August - 1200 UTC 7 August (mm), (b) Same as panel (a), except for 48-h accumulated precipitation difference from 1200 UTC 6 August - 1200 UTC 8 August (mm), (c) Same as panel (a), except for 72-h accumulated precipitation difference from 1200 UTC 6 August - 1200 UTC 9 August (mm), and (d) Taiwan topography (m). Positive values indicate the prediction was larger than the observations. Note that the contour levels are different for each precipitation panel.

and interacted with Taiwan's terrain, a similar pattern exists, however a larger deficit begins to appear on the western side of the southern central mountain range (Fig. 6b). After the center of Morakot had exited Taiwan (Fig. 6c), the precipitation deficit becomes significantly larger on the western side of southern central mountain range, and there is a model overprediction in central western Taiwan. The total difference (Fig. 6d) indicates that the quantitative precipitation error between 1200 UTC 7 August and 1200 UTC 9 August was most significant in the total error, particularly in southern Taiwan.

There are a number of factors that contributed to the underprediction in precipitation subsequent to 1200 UTC 7 August, and more significantly, subsequent to 1200 UTC 8 August, in southern Taiwan. One contributing factor (as stated above) is that the simulated TC moved too slow prior to landfall and too fast after landfall in comparison to the best track estimate. Another factor is that the finest resolution mesh of $5-\mathrm{km}$ may not be at high enough resolution to adequately resolve the deep convective features responsible for producing these very large precipitation amounts, or the interaction of the convection and topography leading to localized large precipitation rates. Also, some inaccuracies in the spatial location and timing of convective and stratiform precipitation as Morakot interacted with land (especially in southern Taiwan after landfall; Fig. 3) were likely factors in the quantitative precipitation forecast error. Finally, a possible contribution to the quantitative precipitation forecast error was an inadequate simulation of the interaction of Morakot with large-scale southwest monsoon flow. This is examined in more detail in section $3 \mathrm{~b}$. Indeed, the observations indicate that a peak amount of $641.0 \mathrm{~mm}$ of precipitation was recorded from 1200 UTC 8 August to 1200 UTC 9 August, which was after Morakot made landfall, equating to $25 \%$ of the total peak precipitation recorded from 1200 UTC 6 August to 1200 UTC 9 August.

While we have focused our analysis on the 1200 UTC 6 August COAMPS-TC forecast, as discussed earlier, COAMPS-TC was run in real time for Typhoon Morakot for the period of 0000 UTC 4 August (the cold start) through 1200 UTC 9 August, with a new forecast produced every $12 \mathrm{~h}$. The track and intensity mean absolute errors for all COAMPS-TC simulations of Morakot are shown in Fig. 7 in comparison to other dynamical models using a homogenous sample. The track and intensity data was obtained from the Automated Tropical Cyclone Forecasting system database (ATCF; Sampson and Schrader 2000). In Fig. 7a, the track error is given in comparison to other global and mesoscale operational dynamical models, as well as the consensus (CONW; Elsberry and Carr 2000; Goerss 2000, 2007; Goerss et al. 2004). The global models are the National Centers for Environmental Prediction (NCEP) Global Forecast System (GFS) and NOGAPS. The mesoscale model is the National Oceanic and Atmospheric Administration (NOAA) Geophysical Fluid Dynamics Model (GFDN; Kurihara et al. 1998) which uses NOGAPS for boundary conditions (similar to COAMPS-TC). In Fig. 7b, the COAMPS-TC intensity error is given in comparison to GFDN. The COAMPS-TC track errors were 80, 195, and $240 \mathrm{~km}$, for lead times of 24,48 , and $72 \mathrm{~h}$, respectively. These track errors were similar to the track consensus and GFS (at early times), and smaller than GFDN and NOGAPS. The COAMPS-TC intensity errors for Morakot were approximately 6,9 , and $21 \mathrm{kt}$ for the lead times of 24,48 , and $72 \mathrm{~h}$, respectively. These intensity errors were significantly smaller than those of GFDN. In summary, COAMPS-TC made accurate predictions of the track and intensity of Morakot through its entire life cycle. 
(a)
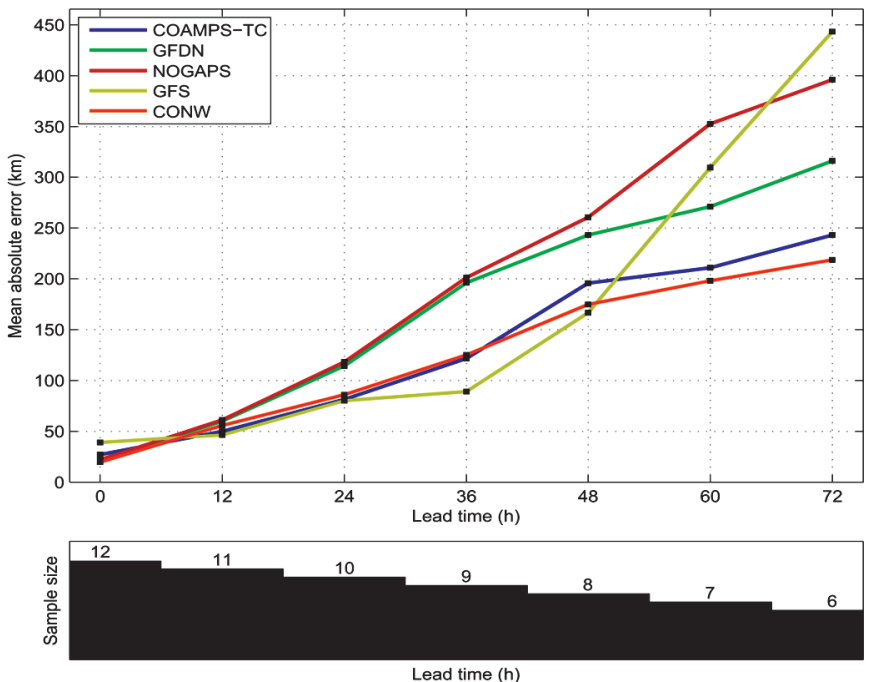

(b)

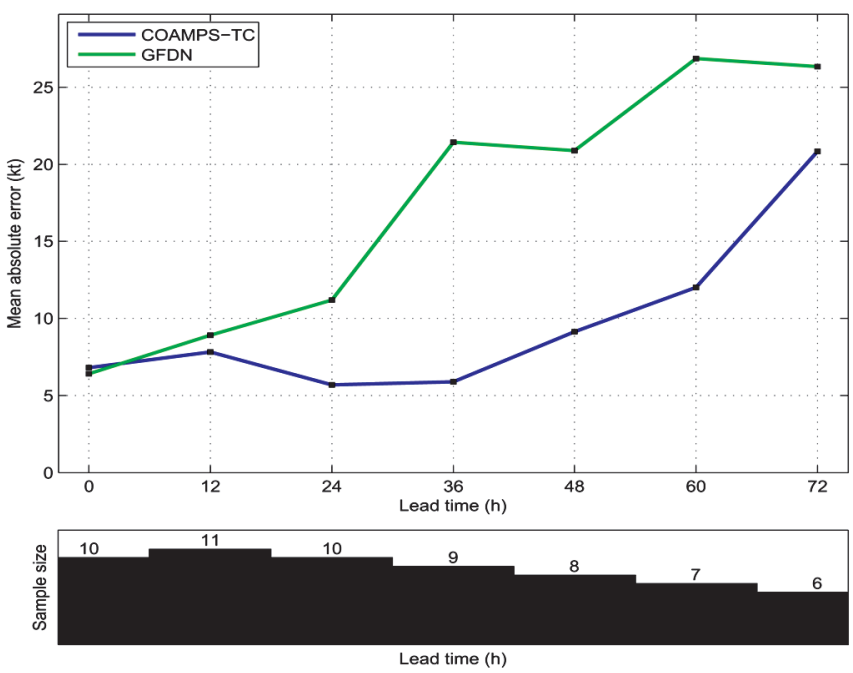

Fig. 7. Track and intensity mean absolute errors for all COAMPS-TC forecasts of Typhoon Morakot from 0000 UTC 4 August through 1200 UTC 9 August, at $12 \mathrm{~h}$ intervals. Panels: (a) track error in comparison to GFS, NOGAPS, GFDN, and the consensus (CONW), (b) intensity error by maximum sustained 1-minute wind at the surface in comparison to GFDN. The sample size (i.e., the number of cases at each lead time in the homogenous sample) is indicated below each plot.

\subsection{Large-Scale Flow Evolution}

In the previous section, detailed analysis of the 5-km domain was provided to assess the numerical model's ability to predict the track, intensity, structure and precipitation of Morakot. In this subsection, large-scale influences to the precipitation are examined using the outermost $45-\mathrm{km}$ domain and observations. Since Typhoon Morakot made landfall in early August, a potential contributing factor to the large precipitation in the southern portion of the central mountain range was the interaction of the TC circulation with the East Asian monsoon. During the warm season from June to August, the East Asian monsoon causes a large region of southwesterly flow over Taiwan creating upslope flow and enhanced precipitation on the western periphery of Taiwan (Chen and Chen 2003). Additionally, two other TC circulations were present in the monsoon gyre with Morakot (Goni and Etau), contributing to the large-scale evolution.

In Fig. 8a, the three $850 \mathrm{hPa}$ vorticity centers of Goni, Morakot, and Etau are evident at 1200 UTC 6 August. The westernmost center at $110^{\circ} \mathrm{E}$ and $22^{\circ} \mathrm{N}$ is associated with tropical depression Goni as it has made landfall in southeastern China. Typhoon Morakot is in the center (with the two nested COAMPS-TC grids located over it) at $125^{\circ} \mathrm{E}$ and $24^{\circ} \mathrm{N}$. Finally, the vorticity center at $140^{\circ} \mathrm{E}$ and $20^{\circ} \mathrm{N}$ is the circulation that eventually becomes tropical storm Etau. All three of these circulations were embedded within the largescale monsoon gyre (Lander 1994) at this time. Since Morakot was the largest and strongest circulation, it advected the other two circulations around itself in time, enhancing the moisture content in the gyre. The advection of Goni and Etau is clearly shown in Fig. $8 b$ at $t=30$ h. The large cyclonic circulation has advected the remnants of Goni toward the western slopes of Taiwan, increasing the moisture content and vorticity there. Similarly, Etau is advected on a more northwestward track by Morakot in the monsoon gyre.

A comparison of the COAMPS-TC 48-h forecasted $850 \mathrm{hPa}$ geopotential height with the NOGAPS global analysis, valid at 1200 UTC 8 August (after Morakot made landfall), is shown in Fig. 9. In the COAMPS-TC forecast, the Goni remnants either merged with Morakot or dissipated between $t=36-42$ h. In reality (Fig. 9b), the Goni remnants remained a separate entity near Hainan Island in the South China Sea. The existence of Goni's remants allowed for a southwest extension of Morakot's $850 \mathrm{hPa}$ height depression, and more southwesterly flow to impinge on Taiwan's western slopes. Note that the main reason that Morakot is deeper in the COAMPS-TC forecast than the NOGAPS analysis is because of the higher resolution of COAMPSTC (45-km on Domain 1 versus $1^{\circ}$ in NOGAPS). The interaction of Goni and Morakot had a significant impact on the large scale flow and moisture pattern that developed after Morakot made landfall. In Fig. 10, the COAMPS-TC $\mathrm{t}=$ $48 \mathrm{~h}$ forecast $850 \mathrm{hPa}$ winds (valid on 1200 UTC 8 August) on Domain 1 (45-km resolution) is shown in comparison to the NOGAPS analysis at 1200 UTC 8 August. Qualitatively, many large-scale flow features are captured by COAMPSTC, including the East Asian southwest monsoon flow and the large Morakot circulation. However, COAMPS-TC puts the strongest southwest monsoon flow slightly too far to the south in comparison to the NOGAPS analysis, likely due to the incorrect simulation of the interaction of Goni and Morakot. In Fig. 11, the predicted total precipitable water and winds by COAMPS-TC are shown in comparison to a 
satellite estimate of the observed total precipitable water at 1200 UTC 8 August and 0000 UTC 9 August, respectively. COAMPS-TC predicts the large-scale precipitable water pattern reasonably well with regard to spatial location and magnitude. The largest values of precipitable water (over
$60 \mathrm{~mm}$ ) extended in a southwest to northeast orientation just off the coast of eastern China, through Taiwan, to southern Japan (Fig. 11b). COAMPS-TC predicts this feature, however it is displaced a little too far too the south. The southward displacement of this key feature, along with drier

(a) COAMPS-TC Domain 1 analysis, $\mathrm{t}=0 \mathrm{~h}$, valid 1200 UTC 6 August

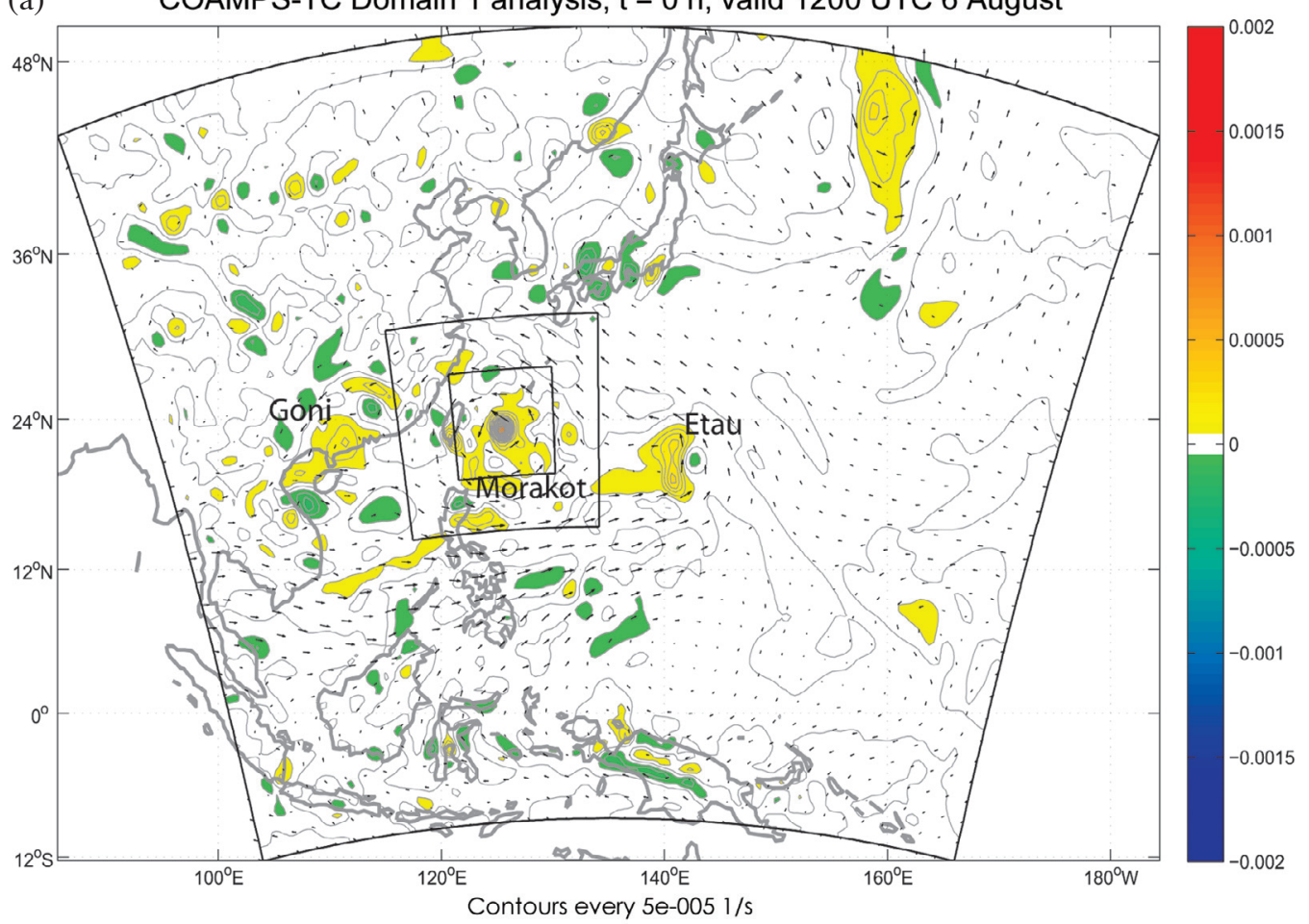

(b) COAMPS-TC Domain 1 forecast, $\mathrm{t}=30 \mathrm{~h}$, valid 1800 UTC 7 August

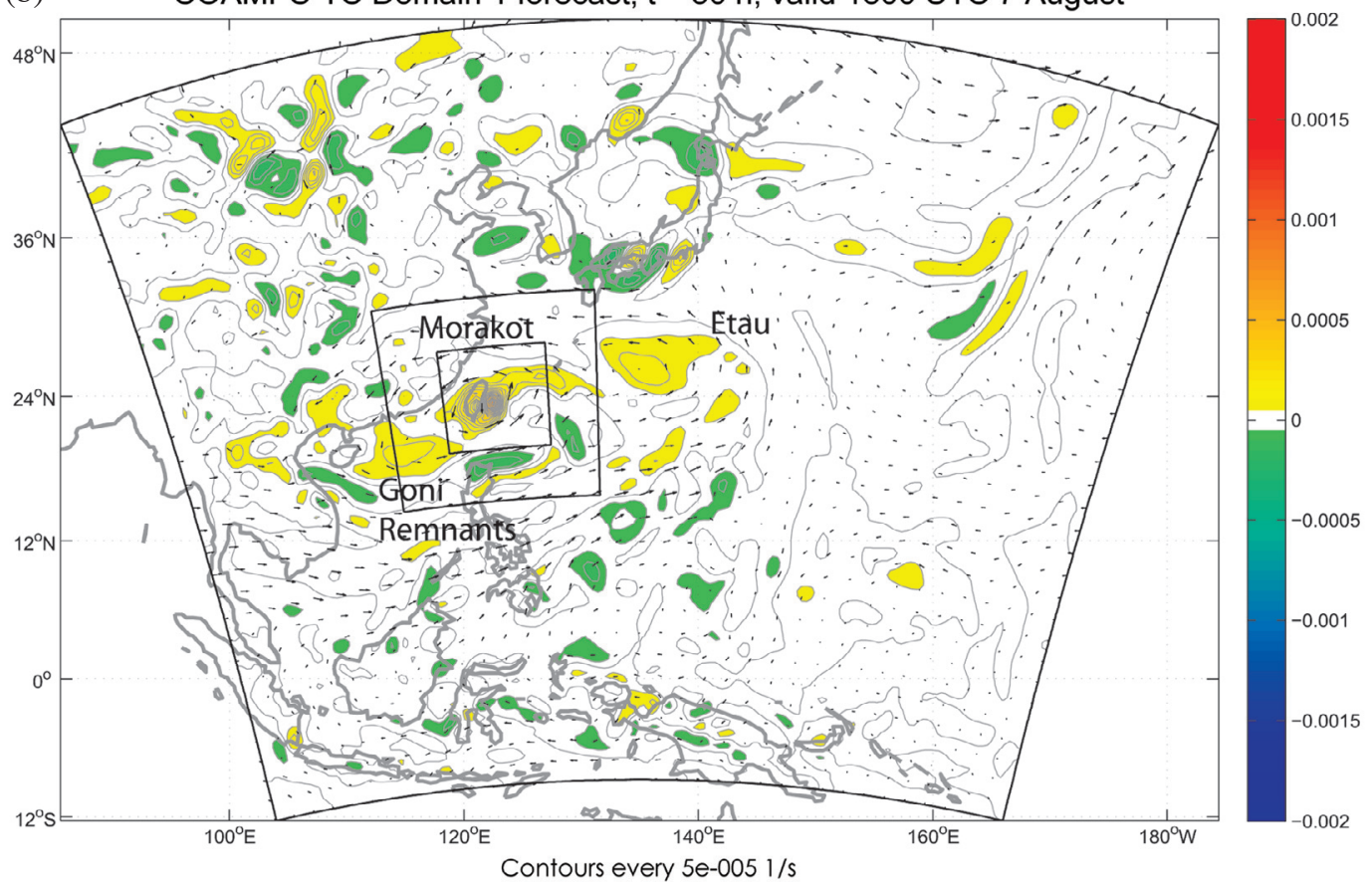

Fig. 8. $850 \mathrm{hPa}$ relative vorticity and wind vectors on Domain 1 at the analysis time of 1200 UTC 6 August [panel (a)], and at the $\mathrm{t}=30$ forecast time [panel (b)]. The low level circulations associated with Morakot, Goni, and Etau are marked. 
northwesterly flow from mainland China, likely contributed to the underestimate of the precipitation.

In summary, the interaction of tropical storm Goni's remnants, Morakot and the East Asian monsoon contributed to the large-scale flow pattern west of Taiwan after
Morakot made landfall. The existence of Goni's remnants as a separate circulation southwest of Morakot allowed for southwesterly moist flow to impinge on Taiwan's western slopes. In the COAMPS-TC forecast, the earlier merging of Goni's remnants with Morakot caused drier westerly to

(a) COAMPS-TC Domain $1850 \mathrm{hPa}$ Geopotential Height (m), t $=48 \mathrm{~h}$, valid $1200 \mathrm{UTC} 8$ August

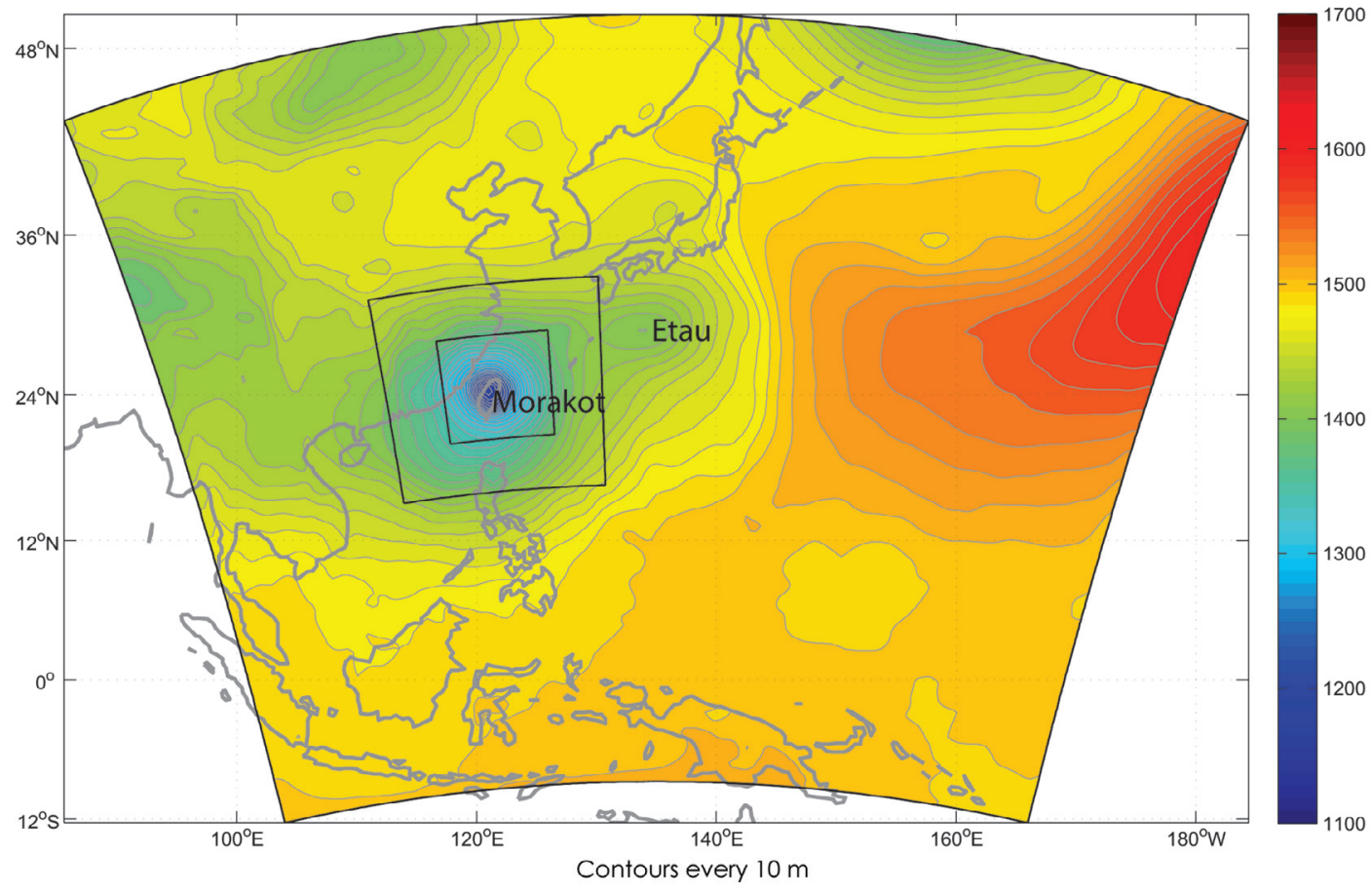

(b) NOGAPS analysis of $850 \mathrm{hPa}$ Geopotential Height (m) at 1200 UTC 8 August

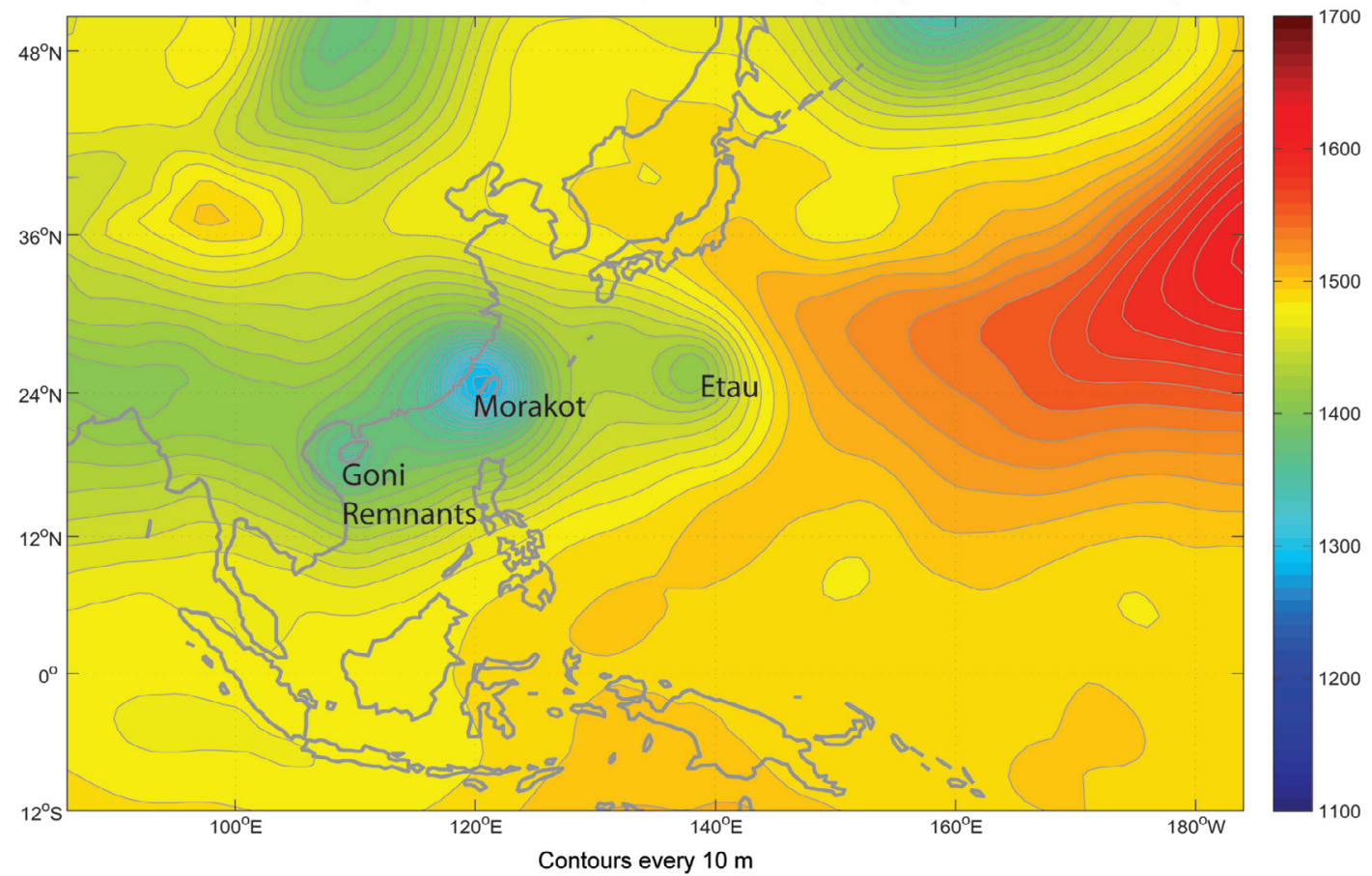

Fig. 9. Panel (a): Comparison of COAMPS-TC $\mathrm{t}=48 \mathrm{~h}$ forecast (valid on $1200 \mathrm{UTC} 8$ August) $850 \mathrm{hPa}$ geopotential height on Domain 1 and, panel (b): NOGAPS global analysis at 1200 UTC 8 August. The low level circulations associated with Morakot, Goni, and Etau are marked. 
northwesterly flow from mainland China to impinge into the South China Sea. The lack of Goni's presence in the COAMPS-TC $48-72 \mathrm{~h}$ forecast is thus a contributing factor to the underprediction of accumulated precipitation in COAMPS-TC.

\section{CONCLUDING REMARKS}

The Naval Research Laboratory's mesoscale tropical cyclone prediction model (COAMPS-TC) was run in real time in the western north Pacific basin in 2009. In this work,

(a) COAMPS-TC Domain $1850 \mathrm{hPa}$ winds $(\mathrm{m} / \mathrm{s}), \mathrm{t}=48 \mathrm{~h}$, valid $1200 \mathrm{UTC} 8$ August

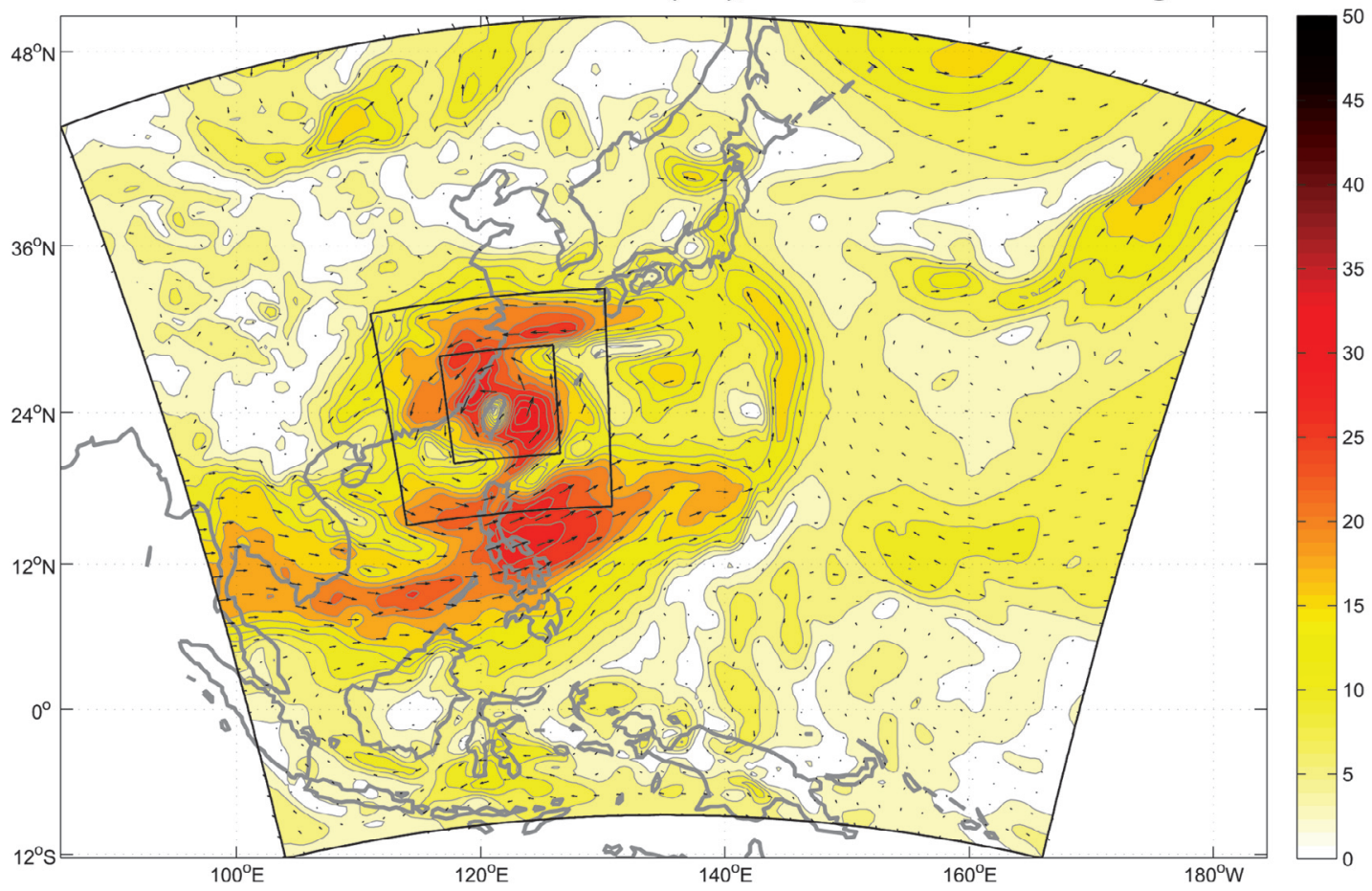

(b) NOGAPS analysis of $850 \mathrm{hPa}$ winds $(\mathrm{m} / \mathrm{s})$ at 1200 UTC 8 August

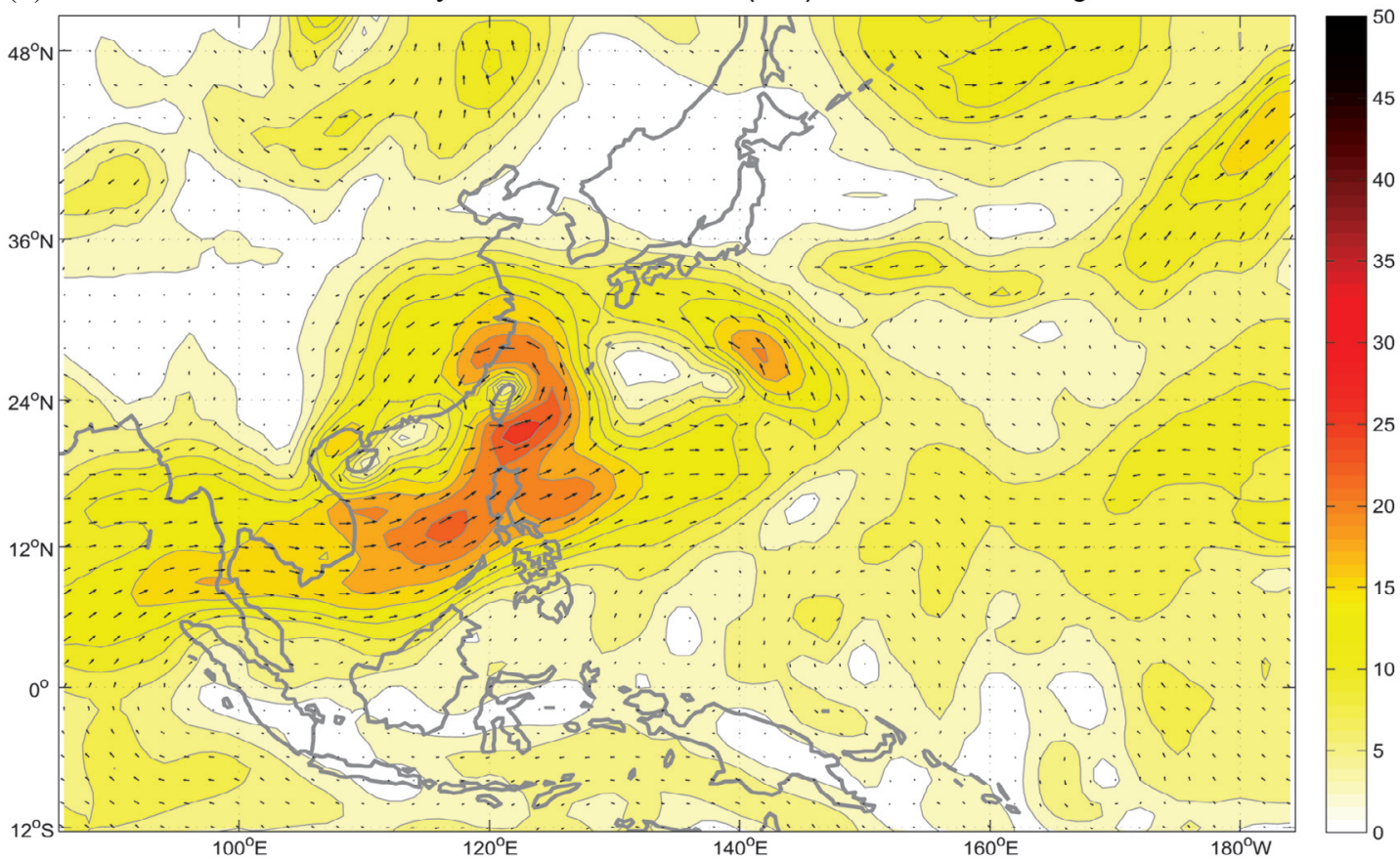

Fig. 10. Panel (a): Comparison of COAMPS-TC $t=48 \mathrm{~h}$ forecast (valid on $1200 \mathrm{UTC} 8$ August) $850 \mathrm{hPa}$ winds on Domain 1 and, panel (b): NOGAPS global analysis at 1200 UTC 8 August. 
(a)
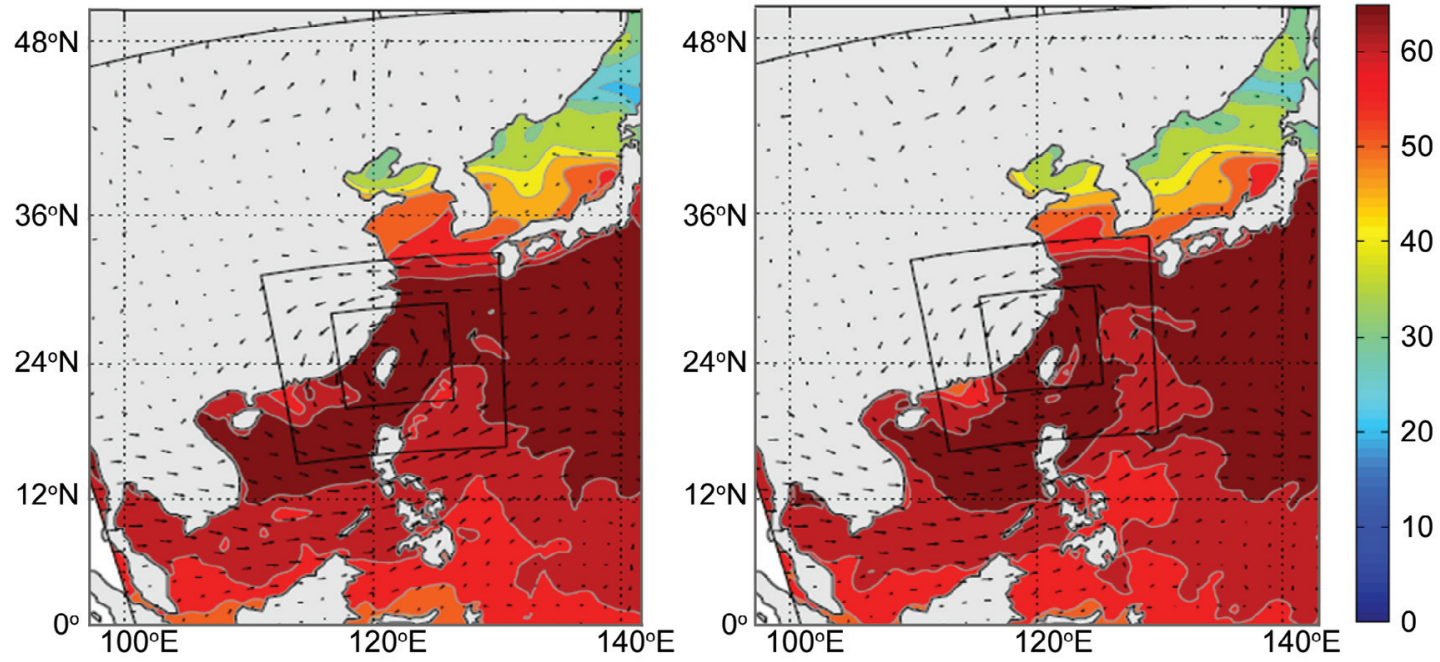

(b)
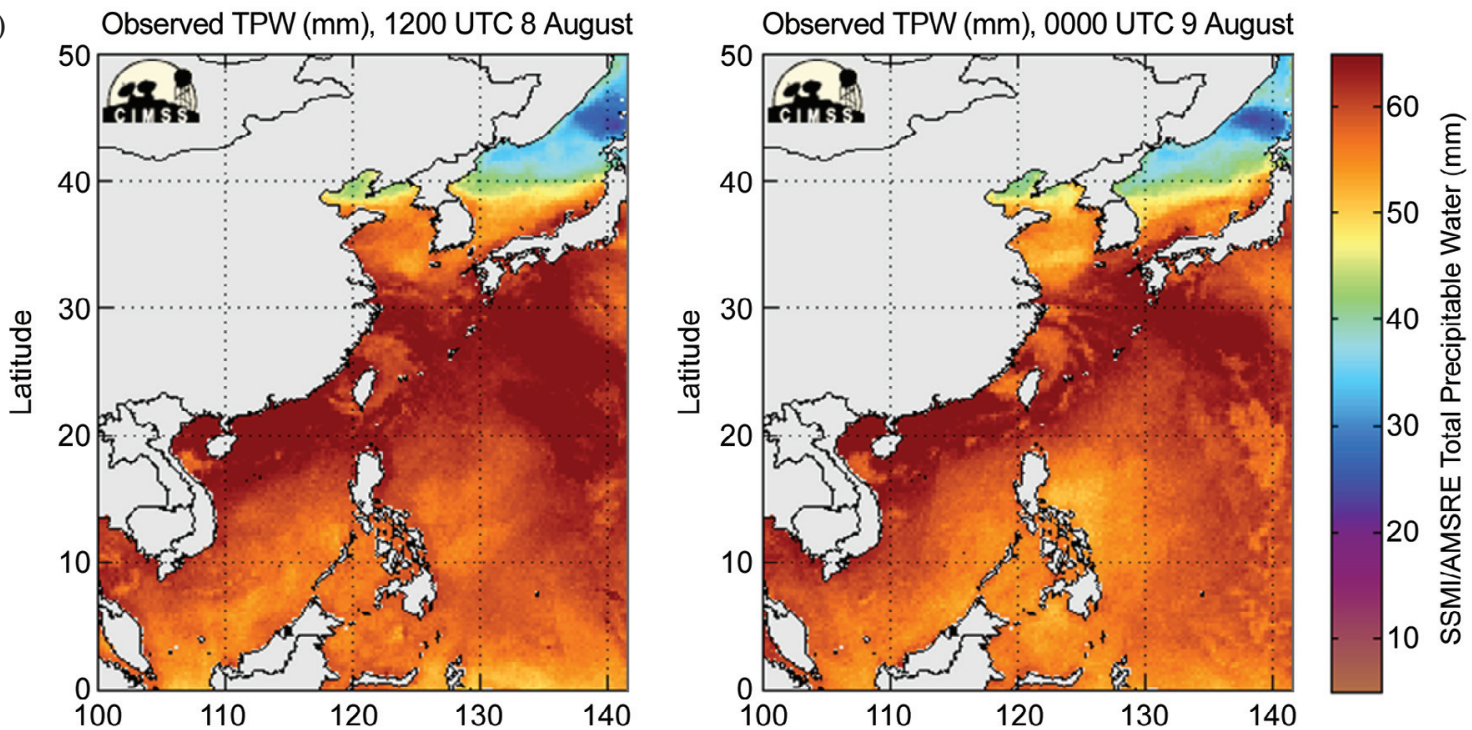

Fig. 11. Panels: (a) Total precipitable water and $850 \mathrm{hPa}$ wind vectors on Domain 1 (45-km horizontal resolution) at t $=48 \mathrm{~h}$ (left) and at $\mathrm{t}=60 \mathrm{~h}$. (b) satellite derived (AMSRE/SSMIS) total precipitable water from CIMSS at corresponding times on 1200 UTC 8 August (left) and 0000 UTC 9 August (right).

an evaluation of the model performance was presented for Typhoon Morakot (2009). The model was evaluated with regard to its ability to predict the track, intensity, structure, and precipitation of the landfalling typhoon. The model performed well with regard to track; track errors were lower than all global and mesoscale dynamical models on average and close to the consensus errors. In addition, COAMPS-TC made very good intensity forecasts for all simulations during the lifetime of Morakot, with a mean absolute error at $\mathrm{t}=$ $48 \mathrm{~h}$ of $9 \mathrm{kt}$. Particular focus was placed on the 72-h simulation beginning on 1200 UTC 6 August, encompassing the time period before, during and after landfall. For this simulation, in a qualitative sense, the simulated structure of Morakot compared well to the observations. COAMPS-TC simulated most of the deep convection and precipitation to the south of the TC, consistent with observations. Additionally, the large size of Morakot was simulated well. The precipitation forecast of Morakot by COAMPS-TC was good in terms of the spatial pattern (capturing the largest precipitation on the upslope western side of the southern portion of the central mountain range), however the peak magnitude of the 72-h accumulated precipitation was approximately half as much as the observed value of $2855 \mathrm{~mm}$. Evidence was presented that most of the quantitative precipitation forecast error in southern Taiwan occurred after Morakot had made landfall in Taiwan due to four main factors and their interplay. First, the southwest monsoon flow was displaced too far south in part because of the premature dissipation 
of tropical storm Goni in the COAMPS-TC forecast. Since $25 \%$ of the peak precipitation was recorded after Morakot had exited Taiwan and was in the Taiwan Strait, an accurate forecast of the interaction of Morakot with the southwest monsoon flow was critical. Second, inaccuracies in the spatial location and timing of convective and stratiform precipitation regions as Morakot interacted with the southern portion of Taiwan's central mountain range was a significant factor in the quantitative precipitation forecast error. Third, the simulated storm moved slightly too slow prior to landfall and slightly too fast afterwards, contributing to an underprection. Finally, it is possible that the horizontal resolution $(5-\mathrm{km})$ was too coarse to resolve the interaction of convection with the complex steep topography, leading to localized extreme precipitation regions.

In future work, sensitivity tests will be conducted on aspects of the resolution, physics, and initial conditions in order to better understand to which parameters the precipitation forecast is most sensitive. First, since the current simulation was run at $5-\mathrm{km}$ horizontal resolution on the finest mesh, it is likely that higher resolution simulations will better resolve the convection, terrain and interaction thereof, yielding an improved precipitation forecast. Second, since the large-scale flow and moisture patterns appear to be important for Morakot's precipitation, it would be interesting to examine the precipitation sensivity to variances in the large-scale moisture content. Third, since the precipitation forecast was found to be sensitive to interaction of Morakot with tropical storm Goni's remnants, it would be interesting to more accurately represent Goni in the initial condition through a fixed high resolution nest. Fourth, a highresolution simulation with ocean coupling may enhance our knowledge of the importance of atmosphere-ocean interaction in numerical precipitation forecasts. Fifth, it is possible that the complicated physical processes during landfall were not represented realistically enough by the model boundary layer and microphysical schemes; future sensitivity tests along these lines are also warranted. Finally, while we have focused on deterministic runs here, future work will also focus on ensemble methods to account for the stochastic nature of convective and precipitation processes in typhoons.

Acknowledgements We are grateful to Brian Billings for his comments and assistance. We also thank Chun-Chieh $\mathrm{Wu}$ and the Central Weather Bureau of Taiwan for providing the rain gauge data, and Charles Sampson for helpful discussions. This manuscript was improved by the insightful comments of two anonymous reviewers. We acknowledge support through the Office of Naval Research's Program Elements $0601153 \mathrm{~N}$ and $0603207 \mathrm{~N}$. We also appreciate support for computational resources through a grant of Department of Defense (DoD) High Performance Computing time from the DoD Supercomputing Resource Center at Stennis, MS. COAMPS $₫$ is a registered trademark of the Naval Research Laboratory.

\section{REFERENCES}

Bender, M. A., R. E. Tuleya, and Y. Kurihara, 1987: A numerical study of the effect of island terrain on tropical cyclones. Mon. Weather Rev., 115, 130-155, doi: 10.1 175/1520-0493(1987)115<0130:ANSOTE>2.0.CO;2. [Link]

Chang, S. W. J., 1982: The orographic effects induced by an island mountain range on propagating tropical cyclones. Mon. Weather Rev., 110, 1255-1270, doi: 10. 1175/1520-0493(1982)110<1255:TOEIBA>2.0.CO;2. [Link]

Chen, C. S. and Y. L. Chen, 2003: The rainfall characteristics of Taiwan. Mon. Weather Rev., 131, 1323-1341, doi: 10.1175/1520-0493(2003)131<1323:TRCOT>2.0. CO;2. [Link]

Chen, J. M., T. Li, and C. F. Shih, 2010: Tropical cycloneand monsoon-induced rainfall variability in Taiwan. J. Climate, 23, 4107-4120, doi: 10.1175/2010JCLI33 55.1. [Link]

Chen, S., J. Doyle, R. Hodur, T. Holt, J. Cummings, J. Schmidt, J. Ridout, C. S. Liou, W. Thompson, and M. Liu, 2003: COAMPS version 3 model description: General theory and equations. Naval Research Laboratory Tech. Rep. NRL/PU7500-04-448, 141 pp.

Chen, S. S., J. A. Knaff, and F. D. Marks Jr., 2006: Effects of vertical wind shear and storm motion on tropical cyclone rainfall asymmetries deduced from TRMM. Mon. Weather Rev., 134, 3190-3208, doi: 10.1175/M WR3245.1. [Link]

Daley, R. and E. Barker, 2001: NAVDAS: Formulation and diagnostics. Mon. Weather Rev., 129, 869-883, doi: 10. 1175/1520-0493(2001)129<0869:NFAD>2.0.CO;2. [Link]

Donelan, M. A., B. K. Haus, N. Reul, W. J. Plant, M. Stiassnie, H. C. Graber, O. B. Brown, and E. S. Saltzman, 2004: On the limiting aerodynamic roughness of the ocean in very strong winds. Geophys. Res. Lett., 31, L18306, doi: 10.1029/2004GL019460. [Link]

Dong, M., L. Chen, Y. Li, and C. Lu, 2010: Rainfall reinforcement associated with landfalling tropical cyclones. J. Atmos. Sci., 67, 3541-3558, doi: 10.1175/20 10JAS3268.1. [Link]

Elsberry, R. L., 2002: Predicting hurricane landfall precipitation: Optimistic and pessimistic views from the symposium on precipitation extremes. Bull. Amer. Meteorol. Soc., 83, 1333-1339.

Elsberry, R. L. and L. E. Carr III, 2000: Consensus of dynamical tropical cyclone track forecasts - Errors versus spread. Mon. Weather Rev., 128, 4131-4138, doi: 10.11 75/1520-0493(2000)129<4131:CODTCT>2.0.CO;2. [Link]

Ge, X., T. Li, S. Zhang, and M. Peng, 2010: What causes the extremely heavy rainfall in Taiwan during Ty- 
phoon Morakot (2009)? Atmos. Sci. Lett., 11, 46-50, doi: 10.1002/asl.255. [Link]

Goerss, J. S., 2000: Tropical cyclone track forecasts using an ensemble of dynamical models. Mon. Weather Rev., 128, 1187-1193, doi: 10.1175/1520-0493(2000)128<1 187:TCTFUA $>2.0 . C O ; 2$. [Link]

Goerss, J. S., 2007: Prediction of consensus tropical cyclone track forecast error. Mon. Weather Rev., 135, 19851993, doi: 10.1175/MWR3390.1. [Link]

Goerss, J. S., C. R. Sampson, and J. M. Gross, 2004: A history of Western North Pacific tropical cyclone track forecast skill. Weather Forecast., 19, 633-638, doi: 10.1175/1520-0434(2004)019<0633:AHOWNP>2.0. CO;2. [Link]

Harshvardhan, R. Davies, D. A. Randall, and T. G. Corsetti, 1987: A fast radiation parameterization for atmospheric circulation models. J. Geophys. Res., 92, 1009-1016, doi: 10.1029/JD092iD01p01009. [Link]

Hodur, R. M., 1997: The Naval Research Laboratory's Coupled Ocean/Atmosphere Mesoscale Prediction System (COAMPS). Mon. Weather Rev., 125, 1414-1430, doi: 10.1175/1520-0493(1997)125<1414:TNRLSC $>2.0 . C$ O;2. [Link]

Hogan, T. F. and T. E. Rosmond, 1991: The description of the Navy Operational Global Atmospheric Prediction System's spectral forecast model. Mon. Weather Rev., 119, 1786-1815, doi: 10.1175/1520-0493(1991)119<1 786:TDOTNO>2.0.CO;2. [Link]

Jin, Y., W. T. Thompson, S. Wang, and C. S. Liou, 2007: A numerical study of the effect of dissipative heating on tropical cyclone intensity. Weather Forecast., 22, 950966, doi: 10.1175/WAF1028.1. [Link]

Kimball, S. K., 2008: Structure and evolution of rainfall in numerically simulated landfalling hurricanes. Mon. Weather Rev., 136, 3822-3847, doi: 10.1175/2008MW R2304.1. [Link]

Klemp, J. B. and R. B. Wilhelmson, 1978: The simulation of three-dimensional convective storm dynamics. $J$. Atmos. Sci., 35, 1070-1096, doi: 10.1175/1520-0469 (1978)035<1070:TSOTDC >2.0.CO;2. [Link]

Kubota, H. and B. Wang, 2009: How much do tropical cyclones affect seasonal and interannual rainfall variability over the western north Pacific? J. Climate, 22, 5495-5510, doi: 10.1175/2009JCLI2646.1. [Link]

Kurihara, Y., R. E. Tuleya, and M. A. Bender, 1998: The GFDL Hurricane Prediction System and its performance in the 1995 hurricane season. Mon. Weather Rev., 126, 1306-1322, doi: 10.1175/1520-0493(1998) 126<1306:TGHPSA>2.0.CO;2. [Link]

Lander, M. A., 1994: Description of a monsoon gyre and its effects on the tropical cyclones in the western north Pacific during August 1991. Weather Forecast., 9, 640654, doi: 10.1175/1520-0434(1994)009<0640:DOAM $\mathrm{GA}>2.0 . \mathrm{CO} ; 2$. [Link]
Liou, C. S. and K. D. Sashegyi, 2011: On the initialization of tropical cyclones with a three dimensional variational analysis. Nat. Hazards, doi: 10.1007/s11069-011-98 38-0, in press. [Link]

Liu, C. C., G. R. Liu, T. H. Lin, and C. C. Chao, 2010: Accumulated rainfall forecast of Typhoon Morakot (2009) in Taiwan using satellite data. J. Meteorol. Soc. Jpn., 85, 785-798, doi: 10.2151/jmsj.2010-501. [Link]

Lonfat, M., R. Rogers, T. Marchok, and F. D. Marks Jr., 2007: A parametric model for predicting hurricane rainfall. Mon. Weather Rev., 135, 3086-3097, doi: 10. 1175/MWR3433.1. [Link]

Mellor, G. L. and T. Yamada, 1982: Development of a turbulence closure model for geophysical fluid problems. Rev. Geophys. Space Phys., 20, 851-875, doi: 10.1029/ RG020i004p00851. [Link]

Nguyen, H. V. and Y. L. Chen, 2011: High-resolution initialization and simulations of Typhoon Morakot (2009). Mon. Weather Rev., 139, 1463-1491, doi: 10. 1175/2011MWR3505.1. [Link]

Peng, M. S. and S. W. Chang, 2002: Numerical forecasting experiments on Typhoon Herb (1996). J. Meteorol. Soc. Jpn., 80, 1325-1338. doi: 10.2151/jmsj.80.1325. [Link]

Rogers, R., S. Chen, J. Tenerelli, and H. Willoughby, 2003: A numerical study of the impact of vertical shear on the distribution of rainfall in Hurricane Bonnie (1998). Mon. Weather Rev., 131, 1577-1599, doi: 10.1175//25 46.1. [Link]

Rutledge, S. A. and P. Hobbs, 1983: The mesoscale and microscale structure and organization of clouds and precipitation in midlatitude cyclones. VIII: A model for the "seeder-feeder" process in warm-frontal rainbands. J. Atmos. Sci., 40, 1185-1206, doi: 10.1175/1520-0469 (1983)040<1 185:TMAMSA > 2.0.CO;2. [Link]

Sampson, C. R. and A. J. Schrader, 2000: The automated tropical cyclone forecasting system (version 3.2). Bull. Amer. Meteorol.Soc., 81, 1231-1240, doi: 10.1175/15 20-0477(2000)081<1231:TATCFS $>2.3 . C O ; 2$. [Link]

Wimmers, A. J. and C. S. Velden, 2007: MIMIC: A new approach to visualizing satellite microwave imagery of tropical cyclones. Bull. Amer. Meteorol. Soc., 88, 1187-1196, doi: 10.1175/BAMS-88-8-1187. [Link]

Wu, C. C. and Y. H. Kuo, 1999: Typhoons affecting Taiwan: Current understanding and future challenges. Bull.Amer. Meteorol. Soc., 80, 67-80, doi: 10.1175/15 20-0477(1999)080<0067:TATCUA>2.0.CO;2. [Link]

Yeh, T. C. and R. L. Elsberry, 1993a: Interaction of typhoons with the Taiwan orography. Part I: Upstream track deflections. Mon. Weather Rev., 121, 3193-3212, doi: 10.1175/1520-0493(1993)121<3193:IOTWTT>2 . $0 . \mathrm{CO} ; 2$. [Link]

Yeh, T. C. and R. L. Elsberry, 1993b: Interaction of typhoons with the Taiwan orography. Part II: Continu- 
ous and discontinuous tracks across the island. Mon. Weather Rev., 121, 3213-3233, doi: 10.1175/1520-049 3(1993) 121<3213:IOTWTT>2.0.CO;2. [Link]

Zhang, F., Y. Weng, Y. H. Kuo, J. S. Whitaker, and B. Xie,
2010: Predicting Typhoon Morakot's catastrophic rainfall with a convection-permitting mesoscale ensemble system. Weather Forecast., 25, 1861-1825, doi: 10.11 75/2010WAF2222414.1. [Link] 